\title{
SISTEMAS PETROLÍFEROS ATÍPICOS NAS BACIAS PALEOZOICAS BRASILEIRAS - UMA REVISÃO
}

\author{
ATYPICAL PETROLEUM SYSTEMS IN BRAZILIAN PALEOZOIC BASINS - A REVIEW
}

\author{
Giovani Matte CIOCCARI ${ }^{1,2}$, Ana Maria Pimentel MIZUSAKI ${ }^{1}$ \\ ${ }^{1}$ Programa de Pós-Graduação em Geociências - Instituto de Geociências - Universidade Federal do Rio Grande do Sul. \\ Av. Bento Gonçalves, 9500 - Agronomia, Porto Alegre - RS. Email: giovani.cioccari@ufpel.edu.br; ana.misukari@ufrgs.br \\ ${ }^{2}$ Centro de Engenharias - Universidade Federal de Pelotas (UFP). Rua Benjamim Constant 989, Porto Pelotas - RS.
}

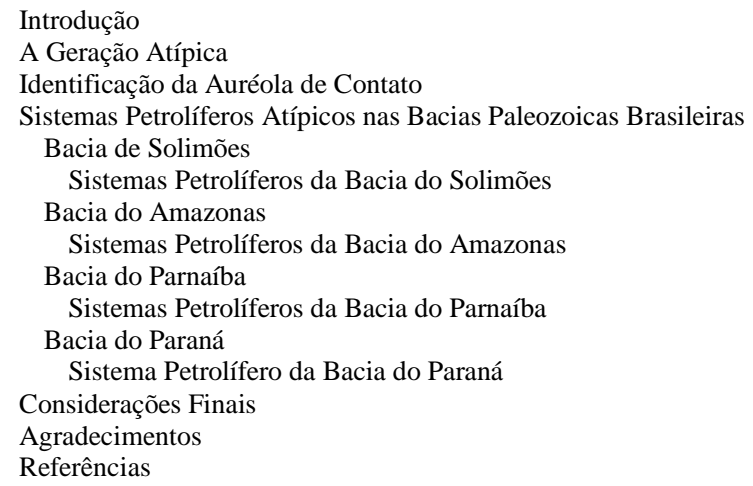

RESUMO - Sistemas petrolíferos atípicos são reconhecidos pelas transformações do conteúdo orgânico ou mineral de rocha encaixante, causada essencialmente pelo efeito térmico da dispersão do calor da soleira ígnea. Pode ser identificado pela auréola de contato, tendo como principal finalidade indicar se a rocha encaixante foi inserida na janela de geração de óleo e gás. O objetivo deste trabalho foi realizar uma revisão bibliográfica sobre os sistemas petrolíferos atípicos das principais bacias paleozoicas brasileiras e contribuir no conhecimento destes sistemas petrolíferos. No Brasil, exemplos de geração atípica ocorrem nas bacias paleozoicas do Solimões, Amazonas, Parnaíba e Paraná com acumulações comerciais e não comercias de óleo e gás. Os intervalos de tempo com maior potencial para existência de rocha geradora nestas bacias são Siluriano, Devoniano e Permiano, que podem estar associados a soleiras com idades em torno de $200 \mathrm{Ma}$ e $130 \mathrm{Ma}$. Conclui-se que nas bacias paleozoicas brasileiras, os sistemas petrolíferos atípicos são: (1) Bacia do Paraná: Vila Maria-Alto Garças/Iapó (.), Vila Maria-Furnas (.), Ponta Grossa-Itararé (!), IratiPiramboia (!) e Irati-Rio Bonito (!); (2) Bacia do Parnaíba: Tianguá-Ipu (!), Tianguá-Jaicós (?), Pimenteiras-Cabeças (!), Pimenteiras-Poti (.), Pimenteiras-Pimenteiras (.) e Longá-Poti (.); e (3) Bacia do Amazonas: Pitanga-Monte Alegre (.), BarreirinhaCuriri (!) e Curiri-Curiri (.); e (4) Bacia do Solimões: Jandiatuba-Juruá (!), Jandiatuba-Uerê (.) e Uerê-Uerê (.).

Palavras-Chave: Efeito Térmico, Geração de Hidrocarbonetos, Sistemas Petrolíferos, Bacias Intraplaca, Soleira Ígnea.

\begin{abstract}
Atypical petroleum systems are recognized by the transformations of organic or mineral content of host rock, caused essentially by thermal effect of the heat dispersion of igneous sill. It can be identified by the contact aureole, whose main purpose is to indicate if the host rock was inserted in oil/gas window generation. The main objective of this work was to carry out a literature review on the atypical petroleum systems of the main Brazilian Paleozoic basins and contribute to the knowledge of these petroleum systems. In Brazil, examples of atypical generation occur in the Paleozoic basins of Solimões, Amazonas, Parnaíba and Paraná with oil and gas accumulations. The time intervals with the greatest potential for source rock in these basins are Silurian, Devonian and Permian, which may be associated with $200 \mathrm{Ma}$ and $130 \mathrm{Ma}$ sills. It is concluded that in the Brazilian Paleozoic basins, petroleum systems are: (1) Paraná Basin: Vila Maria-Alto Garças/Iapó (.), Vila Maria-Furnas (.), Ponta Grossa-Itararé (!), Irati-Piramboia (!), and Irati-Rio Bonito (!); (2) Parnaíba Basin:Tianguá-Ipu (!), Tianguá-Jaicós (?), Pimenteiras-Cabeças (!), Pimenteiras-Poti (.), Pimenteiras-Pimenteiras (.), and Longá-Poti (.); and (3) Amazonas Basin: Pitanga-Monte Alegre (.), Barreirinha-Curiri (!) and CuririCuriri (.); (4) Solimões Basin: Jandiatuba-Juruá (!), Jandiatuba-Uerê (.), and Uerê-Uerê (.).
\end{abstract}

Keywords: Thermal Effect, Hydrocarbons Generation, Petroleum Systems, Intraplate Basins, Igneous Sill.

\section{INTRODUÇÃO}

Petróleo é qualquer tipo de hidrocarboneto de origem natural, explorado e prospectado em bacias sedimentares, quando os elementos essenciais e os processos necessários a sua geração estão presentes (Levorsen, 1957; Magoon \& Dow, 1994). Elementos essenciais são a geradora, o reservatório, o selante e rochas de sobrecarga, e os processos são a geração- migração-acumulação de petróleo e a formação de armadilhas (traps).

O sistema petrolífero é um sistema natural que engloba uma "cozinha geradora ativa" e todo o petróleo gerado, incluindo também todos os elementos e processos geológicos essenciais (Magoon \& Dow, 1994). No entanto, fundamental é que os elementos essenciais e os processos co- 


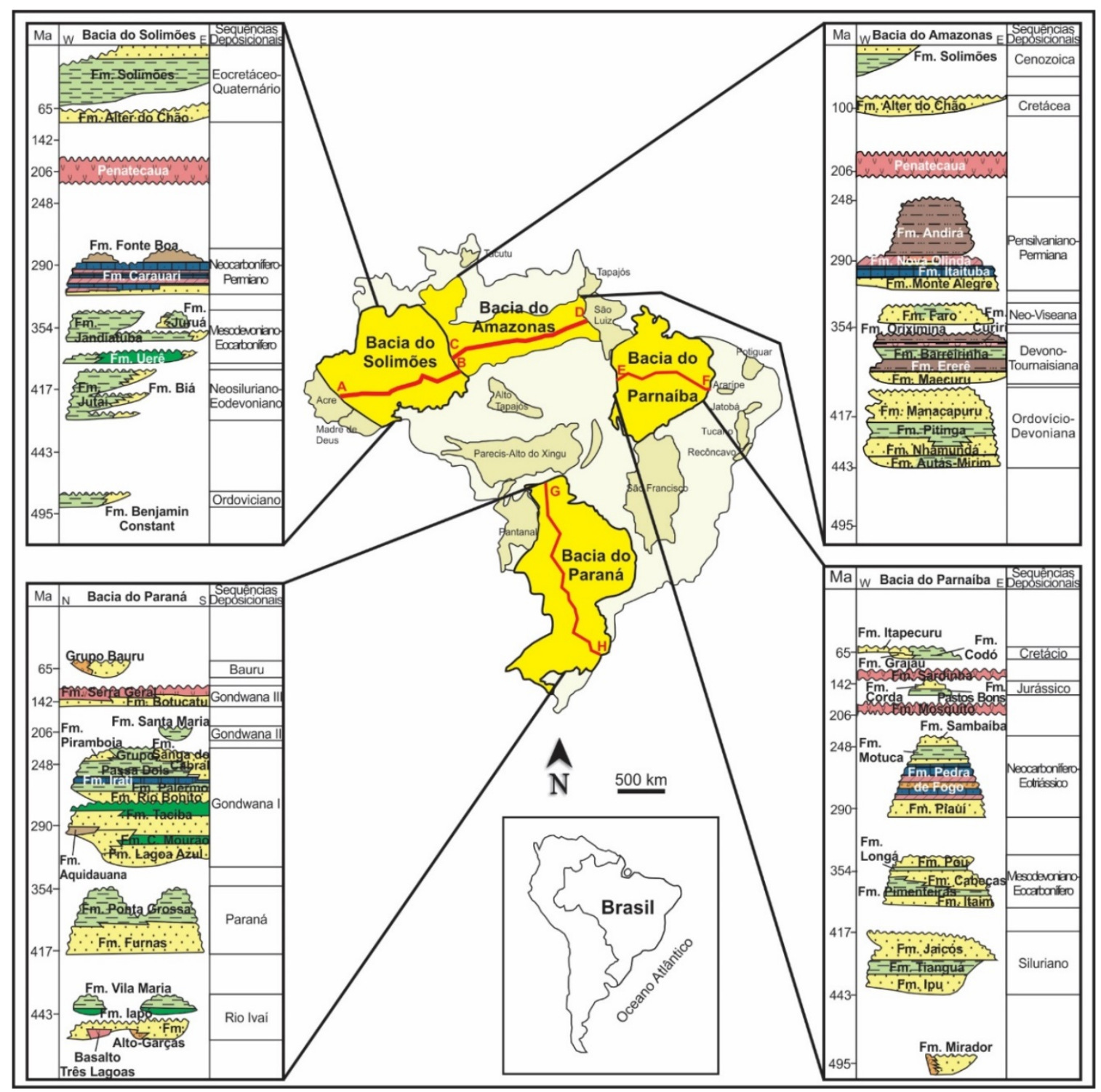

Figura 1 - Localização e cartas estratigráficas das Bacias do Solimões, Parnaíba e Paraná (modificado de Milani et al., 1994, Milani \& Zalán, 1999 e Milani et al., 2007a). Linhas vermelhas indicam a posição das seções geológicas nas bacias do Solimões (A-B), do Amazonas (C-D), do Parnaíba (E-F) e do Paraná (G-H).

existam no tempo e no espaço (timing), para que a matéria orgânica da rocha geradora seja convertida em uma acumulação de petróleo.

O sistema petrolífero descreve a relação genética entre a rocha geradora matura e as acumulações em reservatório relacionadas, podendo ser classificada quanto ao nível de certeza em conhecido (!), hipotético (.) e especulativo (?). O nível de certeza é conhecido (!) quando há uma correlação inequívoca entre o hidrocarboneto armazenado e a rocha geradora. Na ausência desta correlação, mas havendo evidências geoquímicas indicativas da origem do hidrocarboneto, o nível de certeza é hipotético (.). Para o nível de certeza especulativo (?) basta existir evidências geológicas ou geofísicas de uma geradora ou um reservatório. Mas, para todos os níveis de certeza, o principal agente no processo de geração é o incremento da temperatura. O aumento da temperatura em bacias sedimentares ocorre por soterramento ou por intrusão ígnea, sendo os processos de geração denominados de típica e atípica, respectivamente (Magoon \& Dow, 1994; Schutter, 2003). Para nomear um sistema petrolífero, é grafado inicialmente o nome da rocha geradora, separado por hífen, seguido do nome da rocha reservatório, e após o símbolo associado ao nível de certeza do sistema petrolífero, por exemplo, Irati-Piramboia (!).

A geração típica de petróleo é um processo bem definido e conhecido, mas a geração atípica ainda é um tema controverso e discutível. A dispersão do calor da soleira origina mudanças na mineralogia e na matéria orgânica da rocha encaixante resultando na auréola de contato. No Brasil, exemplos de geração atípica ocorrem nas bacias paleozoicas do Solimões, Parnaíba e Paraná (Figura 1) com acumulações comerciais 
atualmente exploradas nas duas primeiras. O objetivo deste trabalho é caracterizar os sistemas petrolíferos atípicos, relacionar com principais eventos magmáticos e identificar os intervalos de tempos das rochas geradoras nas bacias paleozoicas brasileiras.

\section{A GERAÇÃO ATÍPICA}

A geração atípica é um processo que pode ser relevante em bacias sedimentares desde que as rochas geradoras sejam adequadas e a temperatura necessária para maturação não tenha sido atingida durante os processos de subsidência. As intrusões ígneas podem então inserir a rocha geradora na janela de geração de óleo e/ou gás caracterizando a geração atípica de Magoon \& Dow (1994).

Soleiras e diques são os modelos de intrusões ígneas mais comuns e assim denominadas de acordo com a relação concordante ou não com o acamamento das rochas sedimentares (Figura 2). A auréola de contato é mais significativa e gera maior volume de petróleo no caso de uma soleira que possua volume e espessura igual ao de um dique (Quadros, 1976). Inúmeros exemplos são relatados onde a auréola gerada no contato com parte superior da intrusão é maior em relação à parte inferior das soleiras (Anjos, 2008; Wang et al., 2012). Esta constatação é associada ao fluxo de fluidos oriundos da evaporação da água dos poros e da devolatilização mineral da rocha encaixante (Galushkin, 1997; Barker et al., 1998; Makhous \& Galushkin, 2005; Wang et al., 2012). Na porção da encaixante acima da soleira, os fluidos circulam livremente e percorrem distâncias maiores que na porção inferior do pacote sedimentar, funcionando a soleira como uma armadilha e impedindo esta

\section{dinâmica.}

As diferentes proposições sobre a auréola de contato gerada por intrusão ígnea em uma rocha geradora, em função do mecanismo de intrusão magmática, da espessura e temperatura da intrusão, das reações de evaporação da água do poro e devolatilização mineral, das propriedades petrofísicas da rocha encaixante e da soleira, bem como da profundidade de intrusão estão na tabela 1 e figura 3. A auréola de contato gerada pode variar desde metade até mais de três vezes em relação à espessura da intrusão, embora a sugestão preponderante seja que este efeito não é superior a duas vezes a espessura (Figura 3).

Embora a concepção de geração de petróleo por influência da auréola de contato derivada de um único corpo ígneo intrusivo seja aceita, a existência de múltiplas soleiras intrusivas são frequentes e muito importantes do ponto de vista da geração atípica, podendo potencializar o efeito térmico na rocha encaixante.

A influência térmica de múltiplas soleiras pode gerar até $30 \%$ mais petróleo, quando comparada a uma única soleira com espessura semelhante ao somatório das múltiplas. Contudo, existe uma distância considerada ótima de separação entre as múltiplas soleiras, não excedendo a quatro vezes o somatório das espessuras, e culminando com a geração de até 35\% mais petróleo (Aarnes et al., 2011).

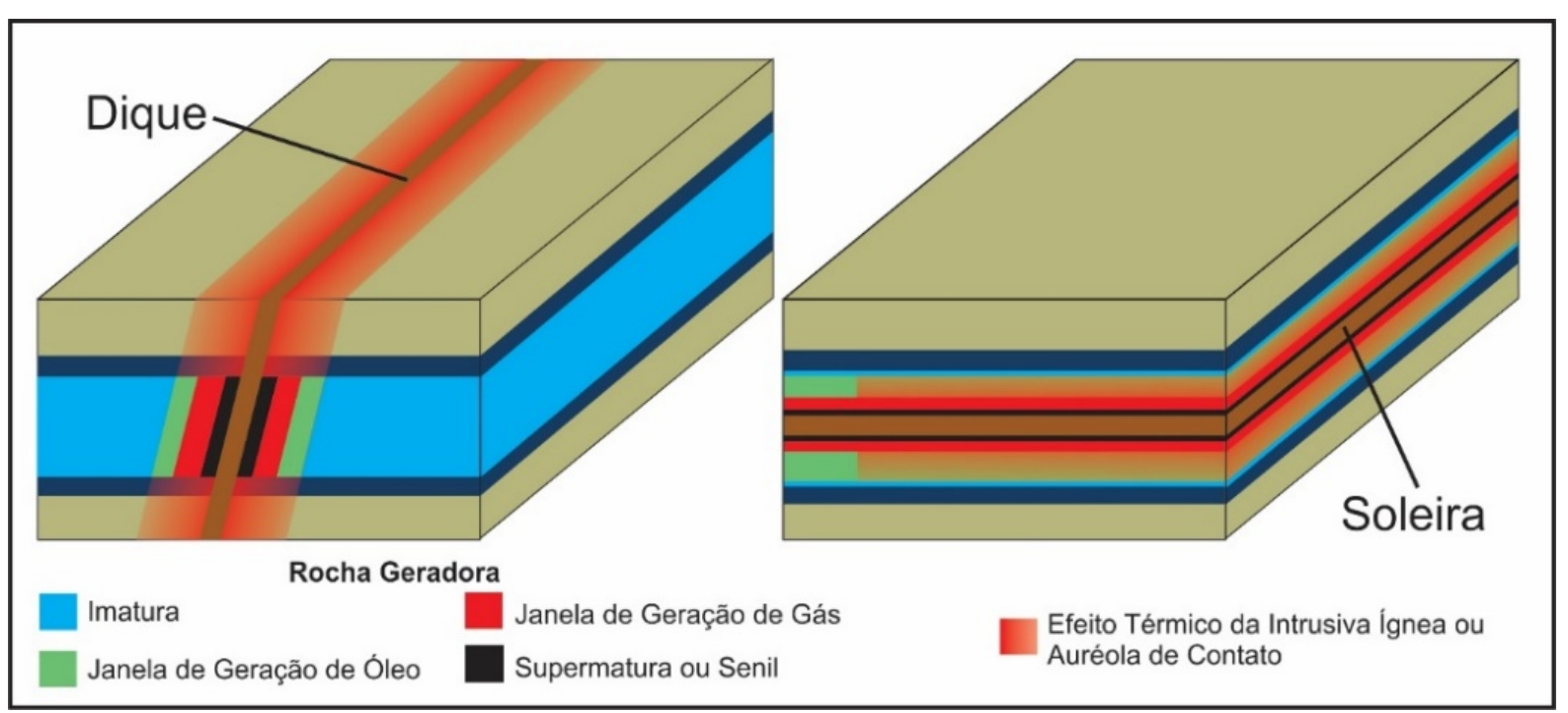

Figura 2 - Dimensionamento da janela de geração de óleo e gás com de acordo com a auréola de contato gerada por intrusão ígnea em forma de dique e soleira. 
Tabela 1 - Compilação bibliográfica contendo informações sobre a auréola de contato e seu comportamento de acordo com as litologias e tipos de intrusão (modificado de Aarnes, 2010).

\begin{tabular}{|c|c|c|c|c|c|c|}
\hline Referência & $\begin{array}{l}\text { Dados de } \\
\text { Modelagem }\end{array}$ & $\begin{array}{l}\text { Técnica } \\
\text { Utilizada }\end{array}$ & $\begin{array}{l}\text { Espessura da } \\
\text { Intrusão (m) }\end{array}$ & $\begin{array}{l}\text { Auréola de } \\
\text { Contato (\%) }\end{array}$ & $\begin{array}{l}\text { Tipo de } \\
\text { Intrusão }\end{array}$ & $\begin{array}{l}\text { Litologia da Rocha } \\
\text { Encaixante }\end{array}$ \\
\hline Aarnes et al. (2011) & T-F-R-Ro- & V-COT-RE & 15,5 & $130-200$ & Soleira & Folhelho Negro \\
\hline Aghaei et al. (2015) & & V-Mi-EL & 1 & $50-200$ & Dique & Lama Carbonosa \\
\hline Alalade \& Tyson (2013) & & COT-RE-Da & * & - & Soleira & Folhelho \\
\hline Agirrezabala et al. (2014) & & V-Mi-COT-RE & 9,86 & $40^{\mathrm{a}}$ & Soleira & Lamito \\
\hline Barker \& Bone (1995) & & Vb-Da & 2,2 & $500 \%$ & Dique & Carbonato Metamórfico \\
\hline Barker et al. (1998) & T-F-Lc & $\mathrm{V}$ & $0,06-40$ & $30-150^{\mathrm{a}}$ & Dique & Argila/sedimentos \\
\hline Bishop \& Abbott (1993) & & COT-RE-CG & 0,9 & $100^{\mathrm{b}}$ & Dique & Siltito \\
\hline Bishop \& Abbott (1995) & $\mathrm{T}$ & V-COT-RE-GC & $0,3-3,0$ & $30-70^{\mathrm{a}}$ & Dique & Folhelho/Folhelho Siltoso \\
\hline Brown et al. (1994) & T-Ro & $\mathrm{V}$ & $40-60$ & $150^{\mathrm{a}}$ & Soleira & Folhelho/Carbonato \\
\hline Bostick \& Pawlewicz (1984) & & V & $3,6-10,4$ & $75-100^{\mathrm{a}}$ & Dique & Folhelho/Carbonato \\
\hline Clayton \& Bostick (1986) & & V-RE-GC-Da & 1,3 & $\sim 50^{\mathrm{a}}$ & Dique & Siltito \\
\hline Cooper et al. (2007) & & V-COT-Da & $0,15-1,8$ & $75-110^{\mathrm{a}}$ & Soleira & Carvão/Folhelho Negro \\
\hline Dow (1977) & & $\mathrm{V}$ & 180 & $200^{\mathrm{a}}$ & Soleira & - \\
\hline Drits et al. (2007) & & Mi & $0,5-80$ & $\sim 70^{\mathrm{b}}$ & Soleira & Lamito \\
\hline Dutrow et al. (2001) & T-F-R & COT-Da & 11 & $35-55^{\mathrm{b}}$ & Dique & Carbonato/Siltito \\
\hline Etuk et al. (2008) & & COT & - & - & Dique & Lamito \\
\hline Finkelman et al. (1998) & & V-RE-EL-Mi & 1,5 & $\sim 35^{\mathrm{a}}$ & Dique & Carvão/Coque \\
\hline Fjeldskaar et al. (2008) & T-Ro & $\mathrm{V}$ & 118,5 & $\sim 150^{\mathrm{c}}$ & Soleira & Silte/Folhelho/Arenito \\
\hline Galushkin (1997) & T-F-Lc-Ld-Ro & $\mathrm{V}$ & $0,9-118,5$ & $55-170^{\mathrm{a}}$ & Soleira/Dique & Folhelho Negro/Silte \\
\hline George (1992) & & V-RE-GC-Da & 3,5 & $\sim 70^{\mathrm{a}}$ & Dique & Silte/Folhelho \\
\hline Gilbert et al. (1985) & & GC & 3,5 & $\sim 160^{\mathrm{b}}$ & Soleira & Folhelho Oleígeno \\
\hline Golab et al. (2007) & & Mi-EL-Da & $\sim 0,1-3$ & $\sim 200^{\mathrm{a}}$ & Dique & Carvão \\
\hline Gröcke et al. (2009) & & V-Da & $1,2-1,5$ & $\sim 100^{\mathrm{a}}$ & Dique & Carvão \\
\hline Gurba \& Weber (2001) & & V-EL & $120-160$ & $\sim 50-120^{\mathrm{a}}$ & Soleira & Carvão \\
\hline Jaeger (1959) & T-F-LV & & - & $100^{\mathrm{C}}$ & - & - \\
\hline Leythaeuser et al. (1980) & & COT-LC-GC-R & - & - & Soleira? & Marga \\
\hline Litvinovski et al. (1990) & T-LM-P & & 500 & $>>10^{\mathrm{b}}$ & Dique & Argila/Pumice \\
\hline Mastalerz et al. (2009) & & V-Da & $>1,2$ & $\sim 50^{\mathrm{a}}$ & Dique & Carvão \\
\hline Meyers \& Simoneit (1999) & & COT-RE-Da & 1,5 & $\sim 60^{\mathrm{b}}$ & Soleira & Carvão \\
\hline Othman et al. (2001) & & V-RE-GC & $0,40-15,7$ & - & Soleira & Lamito \\
\hline Perregaard \& Schiener (1979) & & V-GC & 4,5 & $\sim 50^{\mathrm{a}}$ & Dique & Folhelho \\
\hline Peters et al. (1983) & & V-RE-GC & $0,2-15$ & $50-70^{\mathrm{a}}$ & Soleira & Folhelho Negro \\
\hline Polyansky \& Reverdatto (2006) & T-LM-F-R & & 280 & $10-70^{\mathrm{C}}$ & Soleira & Areia/Siltito \\
\hline Quadros (1976) & & $\mathrm{Da}$ & $\sim 75-240$ & $150-300^{\mathrm{b}}$ & Soleira/Dique & - \\
\hline Raymond \& Murchison (1988) & & $\mathrm{V}$ & $50-118,5$ & $\sim 100-200^{\mathrm{a}}$ & Soleira & Folhelho/Silte/Carbonato \\
\hline Rodrigues \& Quadros (1982) & & V-Da-GC & 4,89 & $\sim 140^{\mathrm{a}, \mathrm{b}}$ & Soleira & Folhelho Negro \\
\hline Rodriguez-Monreal et al. (2009) & T-Ro-HC & V-RE-GC & $110-600$ & $50-100^{\mathrm{a}}$ & Soleira & Folhelho Negro \\
\hline Santos et al. (2009) & $\mathrm{T}$ & Mi-EL-ICE & 13 & $\sim 90^{\mathrm{b}}$ & Soleira & Carbonato/ Folhelho Negro \\
\hline Saxby \& Stephenson (1987) & & COT-GC-Da & 3 & $\sim 50^{\mathrm{b}}$ & Soleira & Folhelho Oleígeno \\
\hline Simoneit et al. $(1978,1981)$ & & V-COT-GC-Da & $0,2-15$ & $40-50^{\mathrm{a}}$ & Soleira & Folhelho Negro \\
\hline Snyman \& Barclay (1989) & & $\mathrm{V}$ & - & $50-1400^{\mathrm{a}}$ & Soleira/Dique & Carvão \\
\hline Souza et al. (2008) & & ICE & 13 & $5000 \%$ & - & - \\
\hline Stewart et al. (2005) & & Ro-Mi-EL & 10,1 & $\sim 120^{\mathrm{a}, \mathrm{c}}$ & Dique & Carvão \\
\hline Svensen et al. (2007) & & V-COT-RE & 80 & $\sim 30^{\mathrm{a}}$ & Soleira & Folhelho Negro/Folhelho \\
\hline Sweeney \& Burnham (1990) & T-Ro & $\mathrm{V}$ & 10,4 & $\sim 100^{\mathrm{a}, \mathrm{c}}$ & Dique & Folhelho \\
\hline Wang et al. (1989) & $\mathrm{T}$ & V-Da & $*$ & - & Soleira & Lamito/Siltito/Arenito \\
\hline Wang et al. (2012) & $\begin{array}{l}\text { T-F-LC-LD- } \\
\text { LM-LV }\end{array}$ & ICE & 13 & $\sim 400^{\mathrm{b}, \mathrm{c}}$ & Soleira & Carbonato/ Folhelho Negro \\
\hline Wang \& Song (2012) & $\begin{array}{l}\text { T-F-LC-LD- } \\
\text { LM-LV }\end{array}$ & & 69 & $\sim 30-50^{c}$ & Soleira & Lamito \\
\hline Wang et al. (2013) & $\begin{array}{l}\text { T-F-LC-LD- } \\
\text { LM-LV }\end{array}$ & R-Ro-COT & 0,9 & $75^{c}$ & Dique & Siltito \\
\hline Ujiie (1986) & & R-COT-EL-Da & 17,5 & $\sim 30-60^{\mathrm{a}, \mathrm{b}}$ & Dique & Siltito Turfáceo \\
\hline Xu et al. (2014) & & V-Da-Mi & $*$ & - & Soleira & Carvão \\
\hline Zhang et al.(2015) & & V-Da-Mi & $0-160$ & - & Soleira & Carvão \\
\hline Zhu et al. (2007) & & V-GC-Da & 50 & $\sim 20^{\mathrm{a}}$ & Soleira & Lamito Negro \\
\hline
\end{tabular}

Legenda da Tabela 1 - Modelagem: T - Modelo térmico; F - Efeito de Fluido; LC - Calor Latente de Cristalização; LD - Calor Latente de Desidratação; LM - Calor Latente de Fusão da Rocha Encaixante; LV - Calor Latente de Vaporização; R - Reações Minerais; Ro - Modelo da Vitrinita; HC - Modelagem Geoquímica; P Modelagem de Pressão; Me - Mecânica de Falha, Data: V - Refletância da Vitrinita; Vb - Refletância do Betume; ICE - Î́ndice de Coloração de Esporos; COT - Carbono Orgânico Total; RE - Pirólise Rock-Eval; GC Cromatografia Gasosa e/ou Biomarcadores; Da - Dados Adicionais; Mi - Dados Minerais; EL- Análise Elementar, Auréola: Baseada no perfil da Vitrinita; Baseado em Outras Técnicas; Baseado em Resultados de Modelagem. OBS.: * Poço com várias intrusões 


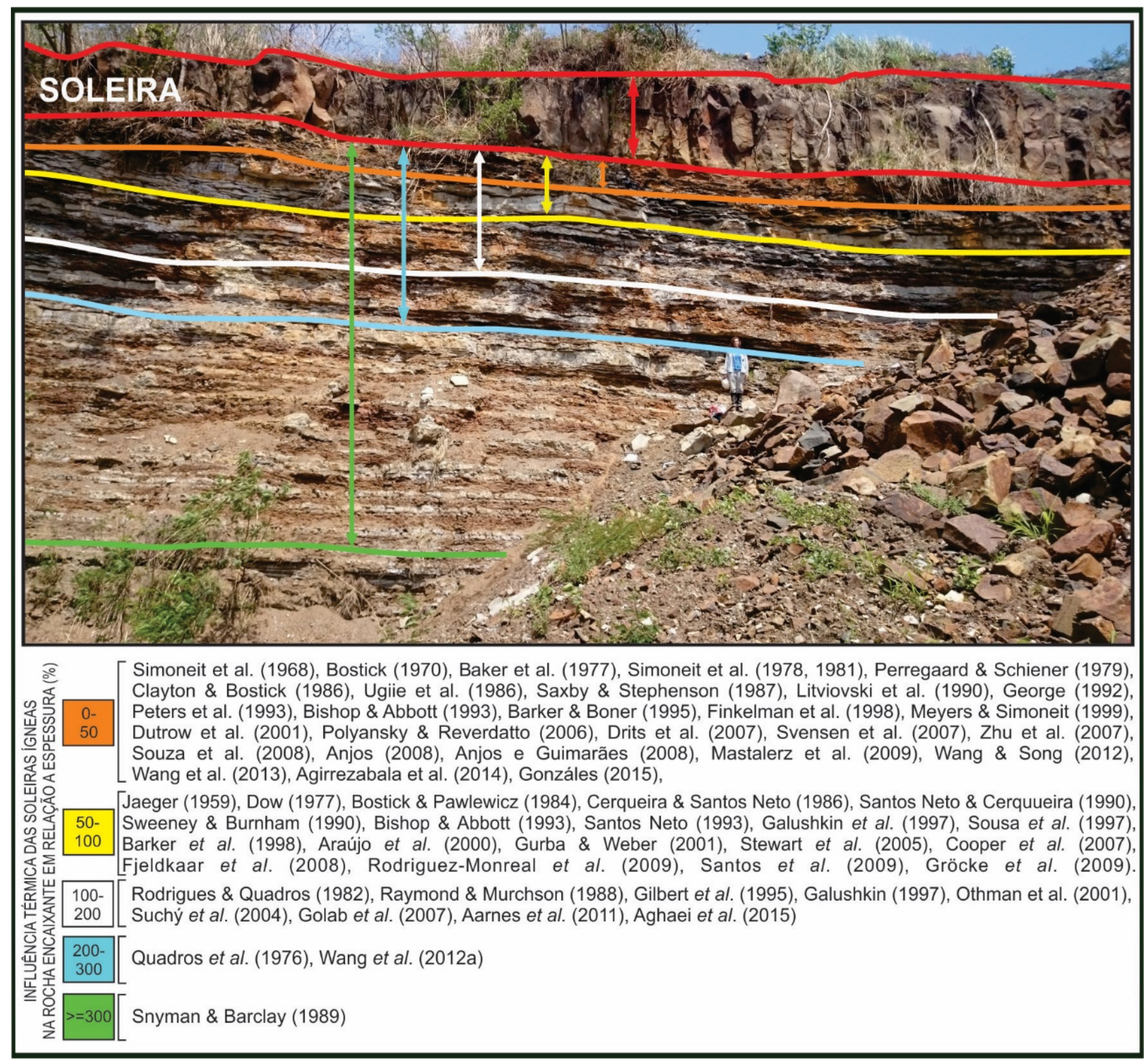

Figura 3 - Auréola de contato hipotética e sua relação com a espessura da soleira (ver Tabela 1).

\section{IDENTIFICAÇÃO DA AURÉOLA DE CONTATO}

O intervalo da rocha encaixante onde ocorrem transformações na mineralogia e na matéria orgânica em função do calor dissipado pela rocha intrusiva é reconhecido como auréola de contato. Um fator relevante é a espessura desta feição que permite inferir o volume de rocha geradora nas janelas de geração de óleo e de gás, e consequente, o volume de petróleo esperado.

Técnicas de petrografia, de geoquímica inorgânica, de geoquímica orgânica e modelagem numérica permitem o seu reconhecimento e caracterização. As análises químicas de rocha, em termos de elementos maiores, traços e terras raras indicam as mudanças na química mineral sob influência do calor da intrusão. As mudanças mineralógicas são identificadas por técnicas de petrografia e de difração de raios $\mathrm{X}$, conforme o tamanho de grão e do grau de cristalinidade de minerais metamórficos de acordo com a intensidade da alteração térmica.

Quanto às técnicas de geoquímica orgânica, que permitem identificar a intensidade da maturação térmica na matéria orgânica, destacam-se a refletância de vitrinita, o índice de coloração de esporos (ICE) e as razões de biomarcadores. A refletância de vitrinita (\%Ro) indica o grau de refletividade da vitrinita, segundo uma escala de $0,2 \%$ a 5,0 \%. O índice de coloração de esporos é obtido pela análise visual em lâminas organo-palinológicas em uma escala entre 0 e 10.

Corresponde ao grau de transmitância dos grãos de pólens e esporos em luz natural transmitida com o incremento da evolução 
térmica, porém limitada a temperaturas inferiores a $250^{\circ} \mathrm{C}$. As razões de biomarcadores como Ts/Ts+Tm, hopanos/esteranos, $\mathrm{C}_{27} / \mathrm{C}_{29}$ esteranos, $\mathrm{C}_{27} 20 \mathrm{~S} / \mathrm{C}_{27} 20 \mathrm{~S}+\mathrm{C}_{27} 20 \mathrm{R}, \mathrm{C}_{29} 20 \mathrm{~S} / \mathrm{C}_{29} 20 \mathrm{~S}+\mathrm{C}_{29} 20 \mathrm{R}$ e $\mathrm{C}_{29} \alpha \beta \beta / \mathrm{C}_{29} \alpha \beta \beta+\mathrm{C}_{\alpha \alpha \alpha}$ mostram o grau de evolução da maturação de acordo com a abundância dos compostos químicos orgânicos cujas estruturas são craqueadas termicamente.

Embora as técnicas de identificação da auréola de contato sejam aplicadas rotineiramente para identificação da maturação, alguns resultados são dúbios ou inconsistentes. Assim, modelos numéricos têm sido utilizados, com simulações através de equações diferenciais que consideram informações como a condutividade térmica, densidade, calor específico da rocha encaixante e da soleira, a temperatura de intrusão, o mecanismo de intrusão magmática, as reações de evaporação da água do poro e devolatilização da rocha encaixante e o calor de cristalização latente do magma da soleira (Galushkin, 1997; Wang et al., 2012, Bostick, 2012).

\section{Sistemas Petrolíferos Atípicos nas Bacias Paleozoicas Brasileiras}

Siluriano, Devoniano e Permiano são os intervalos de tempo com potencial para sistemas petrolíferos atípicos nas bacias do Solimões, Parnaíba e Paraná.

O soterramento nestas bacias não foi adequado para a evolução térmica e maturação da matéria orgânica. No entanto, as intrusões ígneas desempenham papel fundamental no fluxo térmico local ou regional, inserindo as rochas geradoras dentro das janelas de geração de óleo e/ou gás (Rodrigues, 1995; Milani \& Zálan, 1999).

Nas bacias paleozoicas são reconhecidos dois grandes eventos magmáticos com idades em torno de 200 Ma e de 130 Ma. As soleiras e mais raramente diques e derrames com idade de 200 Ma são relacionados ao início de abertura do Oceano Atlântico Norte (Thomaz Filho et al., 2000; Mizusaki et al., 2002; Deckart et al., 2005; Thomaz Filho et al., 2008 a, b). Estes registros são observados na Bacia do Solimões sendo denominado de magmatismo Penatecaua (Issler et al., 1974). Na Bacia do Parnaíba é representado pela Formação Mosquito (Deckart et al., 1999; Marzoli et al., 1999) e até o momento não foi registrado na Bacia do Paraná.

O registro magmático de $130 \mathrm{Ma}$, onde predominam derrames e secundariamente soleiras, representa o início da abertura continental e consequente formação do Oceano Atlântico Sul. Na Bacia do Paraná é a Formação Serra Geral (Thomaz Filho et al., 2000) e na Bacia do Parnaíba é a Formação Sardinha (Marzoli et al., 1999) (Figura 1).

$\mathrm{O}$ efeito térmico destes eventos nas encaixantes sedimentares das Bacias do Solimões, Amazonas, Parnaíba e Paraná pode ser reconhecido pela aplicação de diferentes técnicas analíticas (Alves \& Rodrigues, 1985; Santos Neto, 1993; Rodrigues, 1995; Araújo et al., 2000; Araújo, 2001; Wanderley Filho et al., 2006).

As variações nas auréolas de contato pelo efeito térmico das intrusões ígneas podem causar mudanças na matéria orgânica das geradoras destas bacias, com potencialidade de gerar quantidades significativas de petróleo (Araújo et al., 2000; Thomaz Filho et al., 2008b). No entanto, a caracterização da geradora e do reservatório dos sistemas petrolíferos atípicos nas bacias paleozoicas Solimões, Amazonas, Parnaíba e Paraná é importante para o entendimento do processo de geração atípica e da formação da auréola de contato.

\section{Bacia do Solimões}

A Bacia do Solimões tem uma área de $440.000 \mathrm{~km}^{2}$ no estado do Amazonas sendo limitada pelos arcos de Iquitos e Purus (Wanderley Filho et al., 2007). As províncias geocronológicas Rio Negro-Juruena e Rondoniense (Tassinari et al., 2000) representam o embasamento e definem uma importante feição tectônica denominada de Arco de Carauari que individualiza as subbacias do Jandiatuba e do Juruá (Figura 4). Embora feições tectônicas e diferenças em relação à maturação do hidrocarboneto sejam reconhecidas nas sub-bacias, o registro litológico é semelhante e no depocentro atinge uma espessura máxima de 5.000 m (Milani \& Zalán, 1998).

Cinco sequências deposicionais, limitadas por discordâncias regionais são reconhecidas na Bacia do Solimões (Figuras 1 e 4): Ordoviciano, Neosiluriano-Eodevoniano, Mesodevoniano-Eocarbonífero, Neocarbonífero-Permiano e Eocretáceo-Quaternário (Wanderley Filho et al., 2007). 


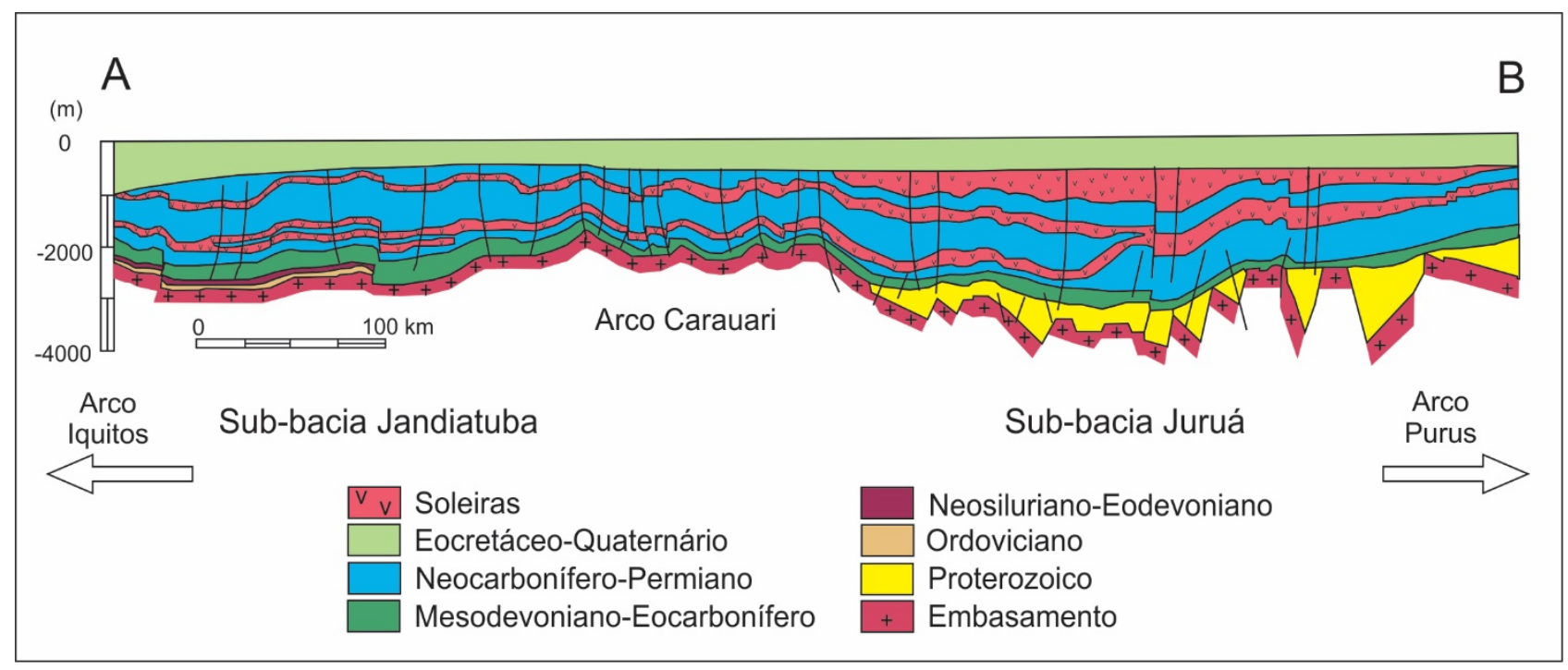

Figura 4 - Seção geológica esquemática da Bacia do Solimões (ver Figura 1) mostrando as sequências deposicionais e as distribuições das soleiras nas rochas sedimentares (modificado de Eiras, 1999).

A sequência ordoviciana é constituída por sedimentos siliciclásticos da Formação Benjamin Constant, sendo restritos a Sub-bacia Jandiatuba e marcam o registro da primeira transgressão marinha fanerozoica.

A sequência do Neosiluriano-Eodevoniano associa-se a novas incursões marinhas com períodos de transgressões e regressões do nível do mar representados por arenitos e sedimentos argilosos, que correspondem às formações Jutaí e Biá (Figura 1).

A sequência do MesodevonianoEocarbonífero é controlada por um conjunto de fatores tectônicos, climáticos e ambientais. $\mathrm{Na}$ Sub-bacia do Jandiatuba predomina sedimentação argilosa de ambiente marinho profundo enquanto na Sub-bacia do Juruá há alternância de sedimentação arenosa com sedimentos argilosos ricos em matéria orgânica e lentes de diamictito, relacionada a um ambiente glacial (Eiras et al., 1994; Wanderley Filho et al., 2007). São reconhecidas duas formações: Jandiatuba e Uerê. A Formação Jandiatuba consiste em folhelhos pretos e diamictitos e a Formação Uerê com sedimentos arenosos e argilosos com espículas silicosas características.

Já a sequência do Neocarbonífero-Permiano tem indícios de associação e deposição em clima quente e árido. A sedimentação arenosa e argilosa da Formação Juruá representa ambiente flúvio-estuarino gradando para eólico costeiro nestas condições paleoclimáticas. A Formação Carauari com predomínio de evaporitos, carbonatos e folhelhos mostra ciclicidade associada a eventos transgressivos-regressivos.
A continentalização da bacia é expressa pelos red beds da Formação Fonte Boa (Figura 1).

Por fim, a sequência do NeocretáceoQuaternário representa a implantação de um sistema fluvial de alta energia com deposição dos sedimentos arenosos da Formação Alter do Chão. No Quaternário, rios deste sistema fluvial tiveram seus gradientes elevados e aumentaram a competência para o transporte de sedimentos resultando nos depósitos essencialmente arenosos que constituem a Formação Solimões (Caputo \& Silva, 1990; Wanderley Filho et al., 2007).

No entanto, a característica principal da Bacia do Solimões são três soleiras com uniformidade química em toda a sua extensão (composição toleítica), relacionadas ao magmatismo Penatecaua (200 Ma). Distribuemse quase continuamente ao longo de toda a área da bacia influenciando na geração de hidrocarbonetos (Figura 4) (Mizusaki et al., 2002; Wanderley Filho et al., 2006).

A geração de hidrocarbonetos na área possui duas fases distintas, a primeira ocorreu no Neopermiano (Barata \& Caputo, 2007) onde os folhelhos geradores da Formação Jandiatuba atingiram o estágio de geração de óleo por soterramento no depocentro da Sub-bacia Juruá. Neste caso, os valores de refletância de vitrinita são inferiores a 1,0\% e a taxa de transformação da matéria orgânica varia entre 40 e 50\% (Eiras, 1998; Garcia et al., 2012), sendo considerada pouco representativa para geração em larga escala.

A segunda fase de geração, NeoperminoEotriássica, é associada às intrusões ígneas que 
geraram anomalias térmicas em toda a área das sub-bacias alcançando até $100 \%$ de taxa de transformação da matéria orgânica, craqueando para condensado e gás (Eiras, 1998; Bender et al., 2001; Wanderley Filho et al., 2007; Barata \& Caputo, 2007; Garcia et al., 2012). A geração, expulsão, migração e acumulação de hidrocarbonetos associada às intrusões ígneas resultam em óleo, condensado e/ou gás acumulados em reservatórios identificados na região do Arco de Carauari e na Sub-bacia Juruá (Figura 4) (Figueiredo \& Milani, 2000).

Os principais sistemas petrolíferos atípicos na Bacia do Solimões são Jandiatuba-Juruá (!) (Eiras, 1998, 1999; Figueiredo \& Milani, 2000), Jandiatuba-Uerê (.) (Eiras, 1998, 1999) e Uerê Uerê (?) (Caputo \& Silva, 1990; Barata \& Caputo, 2007).

De maneira geral, a auréola de contato nas rochas geradoras da Formação Jandiatuba (subbacias Jandiatuba e Juruá) foi mensurada através de refletância de vitrinita sendo no mínimo de 150 \% em relação à espessura da soleira (Mello et al., 1991; Eiras, 1998; Barata \& Caputo, 2007).

O volume de hidrocarbonetos in place na Bacia do Solimões é de aproximadamente 6,86 milhões de metros cúbicos de óleo e 39,2 milhões de metros cúbicos de gás (ANP, 2018a), sendo um exemplo mundial, pela grande quantidade de petróleo gerado pelo efeito térmico de intrusões ígneas (Eiras \& Wanderley Filho, 2003). A produção diária de óleo e gás é de 19,4 mil barris e 11,5 mil metros cúbicos, respectivamente (ANP, 2018b).

Sistemas Petrolíferos da Bacia do Solimões

Os folhelhos da Formação Jandiatuba (Mesodevoniano-Eocarbonífero) constituem o principal gerador de hidrocarbonetos da bacia e representam um evento transgressivo-regressivo em um ambiente marinho costeiro (Caputo \& Silva, 1990; Eiras, 1998; Milani \& Araújo, 2003). Os folhelhos da fase transgressiva apresentam teores de COT entre 2 e $8 \%$, e os da fase regressiva não ultrapassam 1,0\% (Milani \& Araújo, 2003). Porém, a caracterização do tipo da matéria orgânica que constitui a rocha geradora da Formação Jandiatuba na Sub-bacia do Jandiatuba é prejudicada em decorrência da elevada maturação térmica decorrente da influência das intrusivas básicas (Castro \& Silva, 1990). Acredita-se que $40 \%$ do total de hidrocarbonetos gerados na bacia estejam associados à geração por soterramento (primeira fase de geração) e os $60 \%$ restantes relacionamse ao efeito térmico por intrusão ígnea (segunda fase de geração) (Garcia et al., 2012).

A maturação destes folhelhos quando associada ao soterramento apresenta valores de refletância de vitrinita em torno de $1,35 \%$, ou seja, estão inseridos no final da zona matura ou início da zona senil. No entanto, soleiras ígneas disseminadas por toda a bacia geraram consequências secundárias, principalmente na Sub-bacia Juruá e nas proximidades do Alto de Carauari. A influência térmica das soleiras além de afetar os folhelhos geradores também contribui para outros efeitos térmicos. O óleo relativo à primeira fase de geração e já armazenado nos reservatórios é craqueado para condensado e gás pela dispersão térmica das soleiras intrusivas (Castro \& Silva, 1990; Kingston \& Matzko, 1995).

Os folhelhos da Formação Uerê (Mesodevoniano-Eocarbonífero) são considerados como bons geradores, pois apresentam COT variando entre 1,48 e $3,07 \%$ com 75 a 95\% de matéria orgânica amorfa (Caputo \& Silva, 1990). Na Sub-bacia do Juruá, do ponto de vista da evolução térmica, esta formação encontra-se na zona matura.

Porém quando em direção à porção mais central da sub-bacia observa-se elevada maturação térmica e inserção na zona senil com a influência do efeito térmico das soleiras (Barata \& Caputo, 2007).

Nos sistemas petrolíferos atípicos da Bacia do Solimões, os principais reservatórios são os arenitos da Formação Juruá que ocorrem em camadas com até $40 \mathrm{~m}$ de espessura. São arenitos que indicam deposição em um ambiente fluvio-deltaico na base da unidade gradando para um eólico costeiro em direção ao topo. Os arenitos flúvio-deltaicos têm porosidade entre 9 e $11 \%$ e permeabilidade entre 1 e $350 \mathrm{mD}$ (Barata \& Caputo, 2007) e os arenitos associados ao ambiente eólico costeiro possuindo até $22,5 \%$ de porosidade e permeabilidade entre 100 e $320 \mathrm{mD}$ (Eiras et al., 1994; Eiras, 1998; Milani \& Araújo, 2003).

Além de folhelhos geradores, a Formação Uerê tem arenitos que constituem um possível reservatório na bacia (Caputo \& Silva, 1990), com espessuras variando de 20 a $60 \mathrm{~m}$. Caracterizam-se por serem reservatórios heterogêneos, com boa extensão lateral e 
porosidade com valores variando entre $15 \%$ e 28\% (Eiras et al., 1994; De Ros \& Goldberg, 2007; Barata \& Caputo, 2007).

\section{Bacia do Amazonas}

A Bacia do Amazonas é uma bacia intraplaca de $500.000 \mathrm{~km}^{2}$ localizada no norte do Brasil, entre as bacias do Solimões e Marajó. É separada da Bacia do Marajó pelo arco de Gurupá e da Bacia do Solimões pelo arco de Purus (Cunha et al., 1994; Gonzaga et al., 2000).

Os estratos sedimentares estão sobrepostos ao Escudo da Guiana ao norte e Escudo Brasileiro ao sul (Pereira et al., 2012), sendo a porção ocidental da bacia recoberta por sistemas alúvio-flúvio-lacustres tafrogênicos do Grupo Purus (Cunha et al., 1994).

A atual concepção da Bacia do Amazonas (Cunha et al., 1994; 2007) reúne as bacias anteriormente denominadas de Médio e Baixo Amazonas (Caputo, 1984).

$\mathrm{O}$ registro litológico atinge no depocentro espessura máxima de 5.000 m (Milani \& Thomaz Filho, 2000).

Quatro sequências deposicionais, limitadas por discordâncias regionais são reconhecidas na Bacia do Amazonas (Figuras 1,5): OrdovicianaSiluriana, Devoniana-Tournaisiana, NeoViseana e Pensilvaniana-Permiana (Cunha et al., 2007).

C

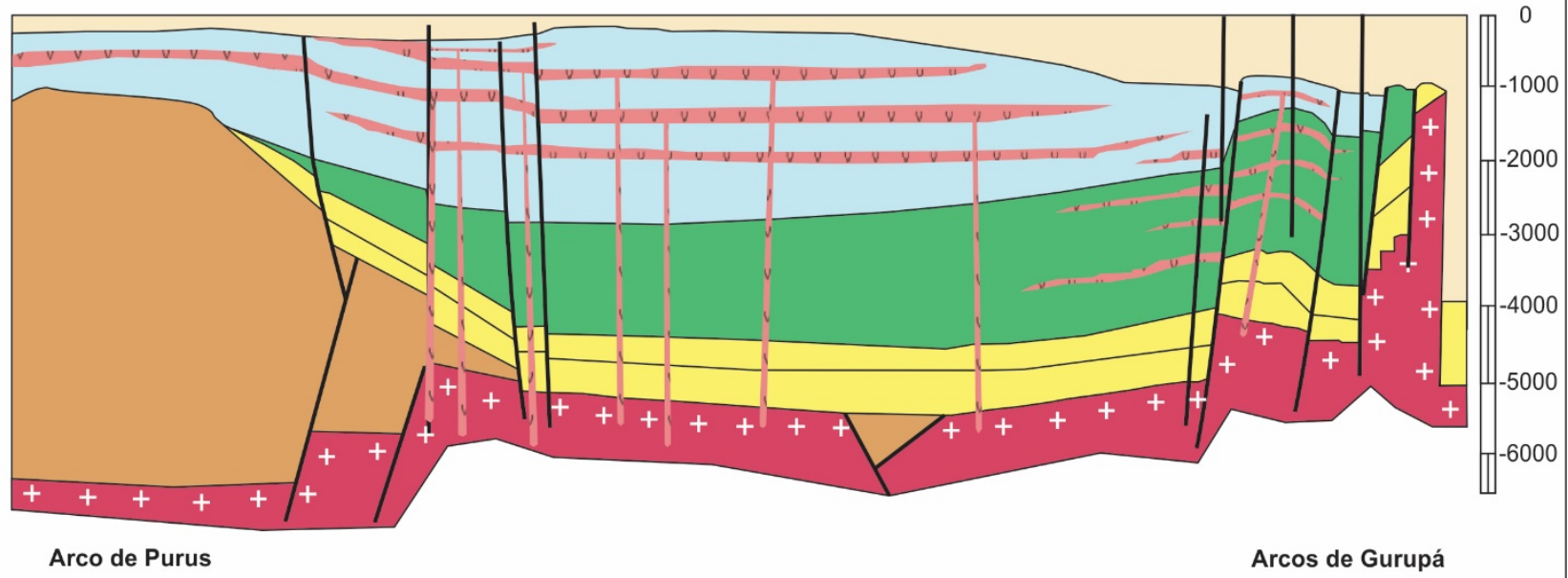

Figura 5 - Seção geológica esquemática da Bacia do Amazonas (ver Figura 1) mostrando as sequências deposicionais e as distribuições das soleiras nas rochas sedimentares (modificado de Wanderley Filho et al., 2006).

A sequência Ordoviciana-Siluriana é constituída por sedimentos siliciclásticos do Grupo Trombetas, constituídos por arenitos marinhos das formações Autas-Mirim, Nhamundá, Manacapuru e siltitos e folhelhos das formações Pitinga Inferior e Pitinga Superior. Representa o estágio inicial de deposição da sinéclise, alternando entre sedimentos glaciais e marinhos com incursões de leste para oeste (Milani \& Thomaz Filho, 2000; Cunha et al., 2007).

A sequência Devoniana-Tournaisiana associa-se a incursões marinhas com ciclos transgressivos e regressivos, registrado na sedimentação marinha com períodos glaciais (Figura 1) dos grupos Urupadi e Curuá. A
Formação Maecuru é composta por arenitos e pelitos e a Formação Ererê por siltito, folhelhos e arenitos, ambas formações depositadas em ambiente nerítico e deltaico (Cunha et al., 1994; 2007).

A sequência Neoviseana é constituída de arenitos e pelitos flúvio-deltaicos e litorâneos com influência de tempestade e possui controle pela intensa atividade tectônica, que atuou nas margens da Placa Sul-Americana, sofrendo soerguimento e erosão em decorrência da orogenia Acadiana ou Chánica (Cunha et al., 1994; 2007).

Por fim, a sequência Pensilvaniana-Permiana constituída pelas rochas sedimentares do Grupo Tapajós, representa um novo ciclo deposicional 
transgressivo-regressivo. A sedimentação arenosa e argilosa da Formação Monte Alegre representa ambiente eólico, intercalados com siltito e folhelhos de lagos. As formações Itaituba e Nova Olinda têm predomínio de carbonatos de inframaré e evaporitos de Sabka, culminando pela continentalização da bacia expressa pelos sedimentos flúvio-lacustres da Formação Andirá (Figura 1).

Assim como a Bacia do Solimões, a Bacia do Amazonas apresenta magmatismo básico (diabásio Penatecaua) no final do Triássico (200 $\mathrm{Ma}$ ), relacionado com a abertura do Oceano Atlântico Norte (Gonzaga et al., 2000; Cunha et al., 2007).

A Bacia do Amazonas possui dois processos de geração de hidrocarbonetos no intervalo Devoniano, um relacionado ao soterramento e outro por efeito térmico de intrusão ígnea (Neves, 1990). Ao longo dos flancos norte e sul e na calha ocidental, onde a Formação Barreirinha encontra-se pouco soterrada (1.500 $m$ de profundidade) a maturação é baixa $(<0,65$ \%Ro). Na calha central da bacia a rocha geradora atinge maturação de $1,0 \%$ Ro a aproximadamente $4.000 \mathrm{~m}$ de profundidade. Gradientes extrapolados dos poços sugerem que a rocha de origem pode chegar a 1,3-1,4 \% Ro no depocentro como resultado do efeito de sobrecarga (Gonzaga et al., 2000). Este autor avalia que os maiores valores de maturação (Ro $>1,4 \%$ ) são decorrentes do efeito térmico de diques e soleiras de diabásio.

O principal sistema petrolífero atípico na Bacia do Amazonas é o Barreirinha-Curiri (!), de acordo com Gonzaga et al. (2000). Este autor observou as auréolas de contato nas amostras das rochas geradoras da Formação Barreirinha (Devoniano) através de refletância de vitrinita, contudo não conseguiu estabelecer relações destas com as espessuras das soleiras.

$\mathrm{O}$ volume de hidrocarbonetos in place calculado para a Bacia do Amazonas expelido pela rocha geradora é de aproximadamente 1,0 bilhão de barris de óleo equivalente (Gonzaga et al., 2000). Descobertas não-comerciais de gás foram obtidas em poços nas regiões de Buiuçu, Cuminá, Faro, Andirá, Fordlândia, Sampaio, e dos Rios Abacaxis e Cupari, e de óleo foram reportadas nas proximidades de Autás Mirim, Andirá e Maués (Ferreira et al., 2015).

Sistemas Petrolíferos da Bacia do Amazonas

A Bacia do Amazonas possui três formações consideradas geradoras: Pitanga, Barreirinha e Curiri. Os folhelhos da Formação Pitanga (Siluriano) variam em espessura de 20 a $40 \mathrm{~m}$ nas bordas, a $120 \mathrm{~m}$ no depocentro da bacia. $\mathrm{O}$ COT geralmente é inferior a $2,0 \%$ e S2 em torno de 4,0 Kg HC/ton de rocha, constituído por querogênio do tipo II indicados por dados de pirólise Rock-Eval. Dados de petrografia orgânica mostram que o querogênio é constituído por uma predominância de liptinita (alta predominância de tasmanites e baixa de palinomorfos e acritarcos) e, subordinadamente matéria orgânica amorfa (Gonzaga et al., 2000).

Os folhelhos negros da Formação Barreirinha (Neodevoniano) constituem o principal gerador de hidrocarbonetos da bacia e representam um evento transgressivo global em um ambiente marinho raso a distal (Cunha et al., 1994). Esta formação é subdivida em duas partes distintas, a seção basal chamada informalmente de "Barreirinhas Inferior" ou "Barreirinha Radioativa” apresentam altos valores de raios gama e resistividade, e a seção superior ou "Barreirinha Superior" compostos por folhelhos cinza escuro (Gonzaga et al., 2000).

Os folhelhos "Barreirinha Inferior" possuem de 30 a $40 \mathrm{~m}$ de espessura média, chegando a 150-160 m no depocentro da bacia. Os teores de COT variam entre 3 e $8 \%$, e S2 em torno de 5 a $23 \mathrm{Kg} \mathrm{HC/ton} \mathrm{de} \mathrm{rocha,} \mathrm{índice} \mathrm{de} \mathrm{hidrogênio}$ (IH) entre 100-450 mg HC/g COT (Tenório, 2013). O querogênio é composto por matéria orgânica amorfa (MOA) e lipitnita, esta última constituída por tasmanites, acritarcas, esporos, polens e cutículas. Através de dados de petrografia orgânica, pirólise Rock-Eval e biomarcadores é interpretado como sendo do tipo II ou II/III (Mullins, 1988; Gonzaga et al., 2000; Tenório, 2013; Calderón et al., 2017; Silva et al., 2017).

Os folhelhos "Barreirinha Superior" possuem em torno de $30 \mathrm{~m}$ de espessura média, chegando a $150 \mathrm{~m}$ no depocentro. Os teores de COT variam entre 1 e $2 \%$, e S2 em torno de $4 \mathrm{Kg}$ $\mathrm{HC} /$ ton de rocha, com baixo $\mathrm{IH}$ de aproximadamente $200 \mathrm{mg} \mathrm{HC/g}$ COT e índice de oxigênio (IO) de $300 \mathrm{mg} \mathrm{CO}_{2} / \mathrm{g}$ COT, composicionalmente apresentando querogênio interpretado como do tipo III através da pirólise Rock-Eval ou oxidado (Gonzaga et al., 2000; Calderón et al., 2017).

Os folhelhos da Formação Curiri (Neodevoniano) possuem baixos teores de COT, 
IH e S2, variando entre 1 e $2 \%$, variando entre 100 e $260 \mathrm{mg} \mathrm{HC} / \mathrm{g} \mathrm{COT}$ e até $3 \mathrm{Kg} \mathrm{HC} /$ ton rocha, respectivamente. $\mathrm{O}$ querogênio é interpretado como do tipo II/III ou oxidados através dos dados de pirólise Rock-Eval, petrográficos e biomarcadores (Trigüis et al., 2005; Garcia, 2014).

A evolução térmica nas rochas geradoras da Bacia do Amazonas possui dois modelos de maturação, um em decorrência da história térmica por subsidência e outra pelo calor de intrusões ígneas (Mullins, 1988; Gonzaga et al., 2000). A integração dos parâmetros ópticos e geoquímicos mostra que a avaliação da evolução térmica ao longo dos flancos norte e sul e na plataforma ocidental da bacia, onde a Barreirinha Inferior é rasa $(1.500 \mathrm{~m}$ de profundidade) a maturação é baixa $(<0,65 \%$ Ro) (Garcia, 2014; Calderón et al., 2017). Na porção central, a maturidade da rocha geradora atinge $1,0 \%$ Ro a cerca de $4.000 \mathrm{~m}$ de profundidade. Os gradientes extrapolados dos poços sugerem que a rocha geradora pode chegar a 1,3-1,4\% Ro no depocentro como resultado do efeito de sobrecarga. Um maior grau de maturação (> 1,4\% Ro) pode ser alcançado em decorrência do efeito de aquecimento causado pelos diques e soleiras de diabásio (Gonzaga et al., 2000).

Nos sistemas petrolíferos da Bacia do Amazonas, as principais descobertas de hidrocarbonetos ocorrem associadas a arenitos das formações Nova Olinda, Monte Alegre e Curiri. Ressalta-se ainda a ocorrência de indícios de óleo e gás em arenitos de diversas unidades estratigráficas, incluindo as formações Itaituba, Faro, Oriximiná, Ererê, Maecuru, Manacapuru e Nhamundá (Figura 1).

Os arenitos e diamictitos da Formação Curiri foram depositadas em vales glaciais escavados em resposta aos rebaixamentos do nível do mar, atingindo valores de porosidade entre 6 e $20 \%$ e de permeabilidade entre 1 e $400 \mathrm{mD}$. Os reservatórios da Formação Monte Alegre, depositados em ambiente desértico continental a transicional do tipo sabkha, exibem sedimentos fluviais e eólicos, com porosidade entre 20 e $25 \%$ e permeabilidades entre 150 e $380 \mathrm{mD}$. A Formação Nova Olinda compreende ciclos de sedimentação siliciclástica, carbonática e evaporítica, sendo os reservatórios formados por arenitos de ambiente parálico, com porosidade alcançando até $20 \%$ e permeabilidade entre 50 e 300 mD (ANP, 2015).

\section{Bacia do Parnaíba}

A Bacia do Parnaíba tem cerca de 600.000 $\mathrm{km}^{2}$ distribuindo-se pelos estados do Tocantins, Pará, Maranhão, Piauí, Ceará e Bahia. O registro vulcano-sedimentar do Ordoviciano ao Terciário tem espessura média de $2.000 \mathrm{~m}$ atingindo $3.500 \mathrm{~m}$ no depocentro da bacia (Góes et al., 1990; Pereira et al., 2012). O arcabouço estratigráfico é dividido em cinco sequências deposicionais (Figuras 1, 6): Siluriano, Mesodevoniano-Eocarbonífero,

Neocarbonífero-Eotriássico, Jurássico, Cretáceo e eventos magmáticos de $200 \mathrm{Ma}$ e de $130 \mathrm{Ma}$.

A sequência siluriana é representada pelas formações Ipu, Tianguá e Jaicós (Figuras 1, 6), com deposição associada a ciclos de transgressão-regressão que representam a primeira incursão marinha na bacia. A Formação Ipu é a unidade mais antiga com arenitos finos, grossos a conglomeráticos atribuídos à sedimentação em diversos ambientes deposicionais como glacial, flúvioglacial e deltaico. A Formação Tianguá reúne folhelhos, carbonatos, arenitos e siltitos gerados em ambiente marinho raso. Os depósitos sobrepostos com camadas de arenitos médios a grossos com eventuais pelitos são associados a um sistema fluvial entrelaçado e relacionados com a Formação Jaicós.

A sequência do Mesodevoniano-Eocarbonífero indica a transição de um ambiente marinho para continental sendo representada pelas formações Itaim, Pimenteiras, Cabeças, Longá e Poti. A Formação Itaim marca um novo ciclo de transgressivo-regressivo, representado por folhelhos e arenitos deltaicos a plataformais afetados por correntes associadas a marés e tempestades. A Formação Pimenteiras composta principalmente por depósitos de folhelhos radioativos ricos em matéria orgânica, intercalados com camadas de siltitos e arenitos registra a incursão marinha mais importante da bacia. A Formação Cabeças mostra uma transição ambiental, sendo constituída por depósitos de arenitos, siltitos, folhelhos e diamictitos de ambiente glacial ou periglacial. $\mathrm{O}$ ambiente de deposição da Formação Longá é plataformal dominado por tempestades, sugerindo uma mudança brusca nos parâmetros ambientais. A Formação Poti exibe características importantes, como eventuais níveis de carvão depositados em ambiente de planície de maré com influência de tempestades (Lima \& Leite, 1978). 


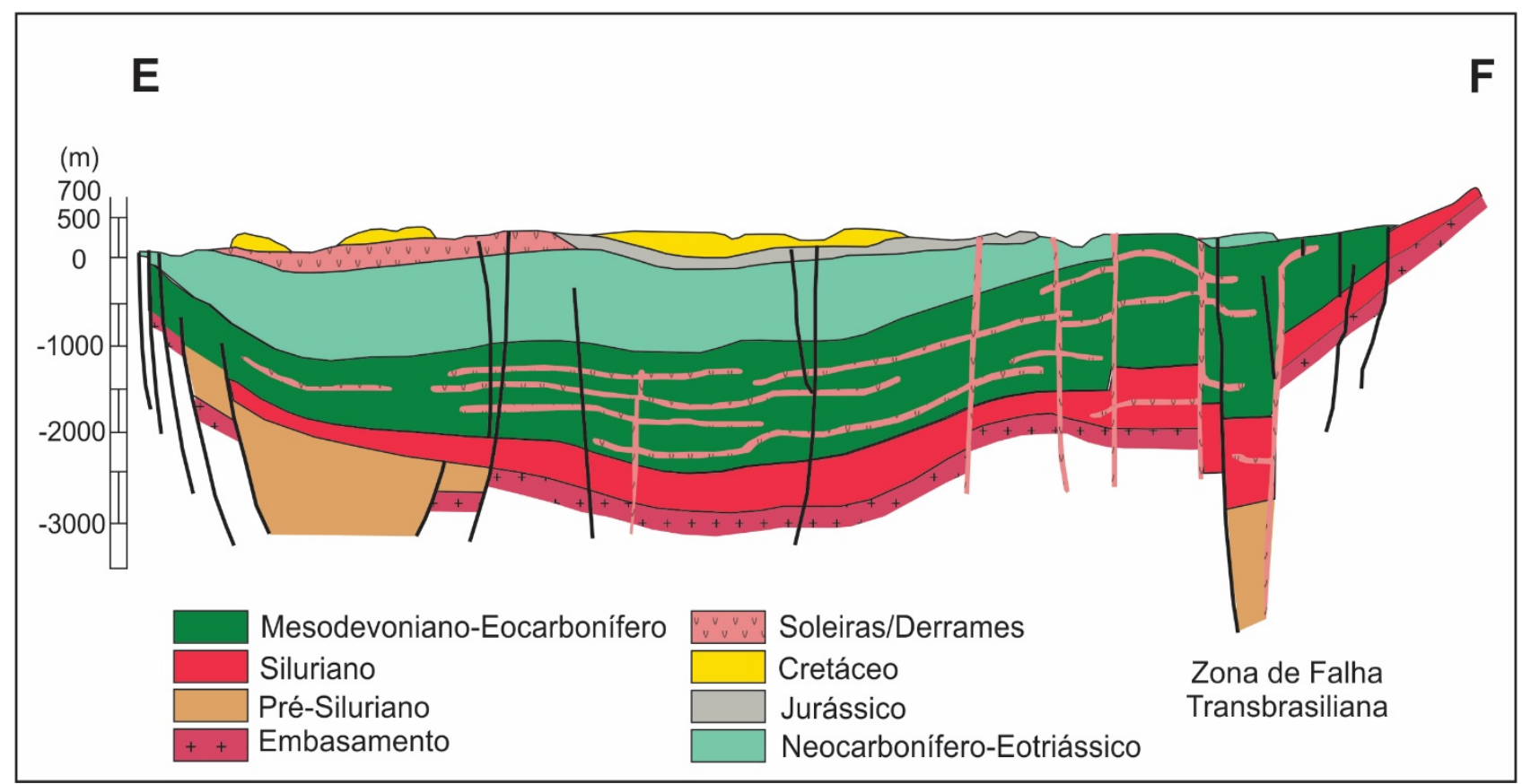

Figura 6 - Seção geológica esquemática da Bacia do Parnaíba (ver Figura 1) mostrando as sequências deposicionais e as distribuições das soleiras nas rochas sedimentares (modificado de Góes et al., 1990).

A sequência deposicional NeocarboníferaEotriássica é representada pelas formações Piauí, Pedra de Fogo, Motuca e Sambaíba. Na Formação Piauí predominam arenitos finos a médios até conglomeráticos, folhelhos e calcários depositados em ambiente continental a litorâneo em condições de aridez. Sobreposto, calcários intercalados com arenitos finos a médios, folhelhos e anidrita de ambiente plataformal raso a litorâneo com planície de sabka sob influência de tempestade caracterizando a Formação Pedra de Fogo. A Formação Motuca tem arenitos, siltitos, folhelhos, anidritas e raros calcários de ambiente continental desértico com eventuais sistemas lacustres. Arenitos eólicos relacionados a um ambiente desértico são registrados na porção superior da sequência NeocarboníferaEotriássica identificando a Formação Sambaíba.

A sequência jurássica tem a Formação Pastos Bons com arenitos finos a médios, lentes de calcário, siltitos, folhelhos depositados em ambiente fluvio-lacustre.

Na sequência cretácea são identificadas as formações Corda, Grajaú, Codó e Itapecuru que marcam um sistema de incursão marinha rasa contiguo ao continental. A Formação Corda tem sedimentação arenosa típica de ambiente desértico gradando para os arenitos médios a grossos com presença de seixos e níveis conglomeráticos associados ao ambiente fluviodeltaico e aluvial da Formação Grajaú. Na
Formação Codó, folhelhos, calcários, siltitos, gipsita, anidrita e arenitos são as litologias mais comuns, com raros níveis de sílex e estromatólitos depositados em ambientes que transitam desde o marinho raso, lacustre até flúvio-deltaico (Rosseti et al., 2001).

Sob o ponto de vista do efeito térmico causado por intrusões ígneas nas rochas geradoras da Bacia do Parnaíba, Rodrigues (1995) relata a presença de auréola de contato com espessuras superiores a $170 \%$ em relação a soleira. Destaca-se que o intervalo final e inicial do processo de geração de hidrocarbonetos situando-se entre $80 \%$ e $140 \%$ da espessura do corpo ígneo intrusivo, respectivamente, contudo não deixa claro quais as formações e locais afetados termicamente pelas intrusões.

De forma excepcional, na Formação Pimenteiras é reconhecida uma auréola de contato com espessura total equivalente a $240 \%$ em relação à soleira com base na maturação térmica indicada pela refletância de vitrinita. Observa-se que a uma distância de até 110 \% da soleira, a rocha geradora está inserida dentro da janela de gás e entre $110 \%$ e $240 \%$ encontra-se na janela de óleo (Miranda, 2014).

Os sistemas petrolíferos atípicos na Bacia do Parnaíba que se destacam são Tianguá-Ipu (?), Tianguá-Jaicós (?), Pimenteiras-Jaicós (?), Pimenteiras-Cabeças (!), Pimenteiras-Poti (!), Pimenteiras-Pimenteiras (?) e Longá-Poti (?).

Registros de produção de hidrocarbonetos da 
Bacia do Panaíba mostram que o volume de óleo e gás in place é de aproximadamente 15 bilhões de $\mathrm{m}^{3}$. A produção diária é de 50 barris de óleo e 6,13 milhões de metros cúbicos de gás (ANP, 2018b).

\section{Sistemas Petrolíferos da Bacia do Parnaíba}

Os principais geradores da bacia são os folhelhos das formações Tianguá, Pimenteiras e Longá. Os folhelhos da Formação Tianguá (Siluriano) tem até $170 \mathrm{~m}$ de espessura com teores de COT em torno de 1,0\%, podendo atingir 1,2\% e índice de hidrogênio de até 397 mg HC/g COT (Rodrigues, 1995; Góes et al., 1990; Costa Jr. \& Magalhães, 2016). O querogênio é composto por liptinita e matéria orgânica amorfa que estão oxidados sendo então inadequados para a geração de hidrocarbonetos (Rodrigues, 1995).

Os folhelhos da Formação Pimenteiras (Devoniano) constituem a principal rocha geradora da bacia, pois além da alta radioatividade apresentam espessuras superiores a 500 m (Góes et al., 1990; Kingstone \& Matzko, 1995). O querogênio é constituído por cerca de $60 \%$ de matéria orgânica amorfa e secundariamente esporos, acritarcos, prasinófitas, cutículas, quitinozoários, resinas e fitoclastos, característicos de querogênio do tipo II e III (Góes et al., 1990; Amaral et al., 2013). Os valores de COT variam entre $0,4 \%$ e $4,8 \%$ com potencial gerador inferior a $1,0 \mathrm{~kg} \mathrm{HC} / \mathrm{t}$ rocha e baixo índice de hidrogênio, variando entre 6 e $50 \mathrm{mg} \mathrm{HC/g}$ COT (Miranda, 2014). Análise do potencial gerador e de maturação térmica realizados em amostras de folhelhos da Formação Pimenteiras, em regiões onde são encontrados campos de produção de gás na bacia, indica que os folhelhos apresentam aproximadamente $2 \%$ de COT e valores de refletância da vitrinita que atestam a influência das soleiras de diabásio em sua maturação térmica (Cunha et al., 2007). Aproximadamente $27 \%$ da área total destes folhelhos geradores são afetados pelo efeito térmico proveniente de soleiras da Formação Mosquito (Jurássico) com consequente geração de petróleo (Kingstone \& Matzko, 1995; Cunha et al., 2012; Miranda, 2014).

Na Formação Longá (MesodevonianoEocarbonífero) são identificados até $150 \mathrm{~m}$ de folhelhos onde teores de COT entre 0,02 \% e 0,61 \% são considerados baixos. Embora não se identifique uma relação direta entre os baixos teores de COT e o eventual efeito térmico atribuído às soleiras, Cardona (2015) relaciona este efeito com a presença de cristais de albita autigênica nos folhelhos seria um indício da circulação de fluidos a partir de intrusões ígneas.

Os potenciais reservatórios da Bacia do Parnaíba são os arenitos das formações Ipu, Jaicós, Cabeças, Pimenteiras, Piauí e Poti. Os arenitos da Formação Ipu possuem até $300 \mathrm{~m}$ de espessura e apresentam relato de acumulação de gás gerado na Formação Tianguá (Porto, 2013). A porosidade média destes arenitos é estimada em 7\% (Batista, 2015), evidenciando um reservatório de péssima qualidade, contudo caracterizando o sistema petrolífero TianguáIpu (?).

Os arenitos da Formação Jaicós tem espessura máxima de 400 m (Caputo \& Lima, 1984). Apesar das evidências sísmicas indicando intrusões de soleiras ígneas nos folhelhos geradores da Formação Pimenteiras (Porto, 2013), ainda não foram encontradas acumulações comerciais ou ocorrências de hidrocarbonetos e assim o sistema petrolífero Pimenteiras-Jaicós é considerado especulativo (?).

Descobertas de gás pela empresa Óleo e Gás Participações S.A. (OGX) identificaram os sistemas petrolíferos Pimenteiras-Poti (!) no campo de Gavião Real (ANP, 2016a) e Pimenteiras-Cabeças (!) no campo de Gavião Azul (ANP, 2016c), ambos no Estado do Maranhão.

Os arenitos reservatório da Formação Poti tem espessuras entre 40 e 140 m (Góes, 1995) e porosidade variando entre 6 e 21\% (ANP, 2016a; 2016b; 2016c; 2016d; 2017).

Os reservatórios da Formação Cabeças são arenitos com cerca de $400 \mathrm{~m}$ de espessura e o gás no campo de Gavião Azul (sistema petrolífero Pimenteiras-Cabeças (!)) foi efetivamente gerado na Formação Pimenteiras pela maturação associada ao efeito térmico de soleiras (Young \& Borghi, 2003; Cunha et al., 2012, ANP, 2016c).

A Formação Pimenteiras tem os folhelhos que são os principais geradores da bacia, mas as camadas de arenitos associadas com espessuras entre 13 e $24 \mathrm{~m}$ constituem um reservatório potencial na bacia (Góes et al., 1990; Young \& Borghi, 2003). A porosidade e permeabilidade médias destes arenitos variam de 20 a $23 \%$ e de 0,1 a $65 \mathrm{mD}$ valores compatíveis com uma rocha reservatório (Young \& Borghi, 2003). 


\section{Bacia do Paraná}

A Bacia do Paraná tem cerca de 1.100 .000 $\mathrm{km}^{2}$ no Brasil e em partes do Paraguai, Argentina e Uruguai. O preenchimento vulcanosedimentar com idades do Siluriano ao Cretáceo atinge $7.000 \mathrm{~m}$ no depocentro da bacia e subdividido nas sequências deposicionais: Rio Ivaí, Paraná, Gondwana I, Gondwana II, Gondwana III e Bauru (Milani, 1997; Milani et al., 2007 a) (Figuras 1, 7).

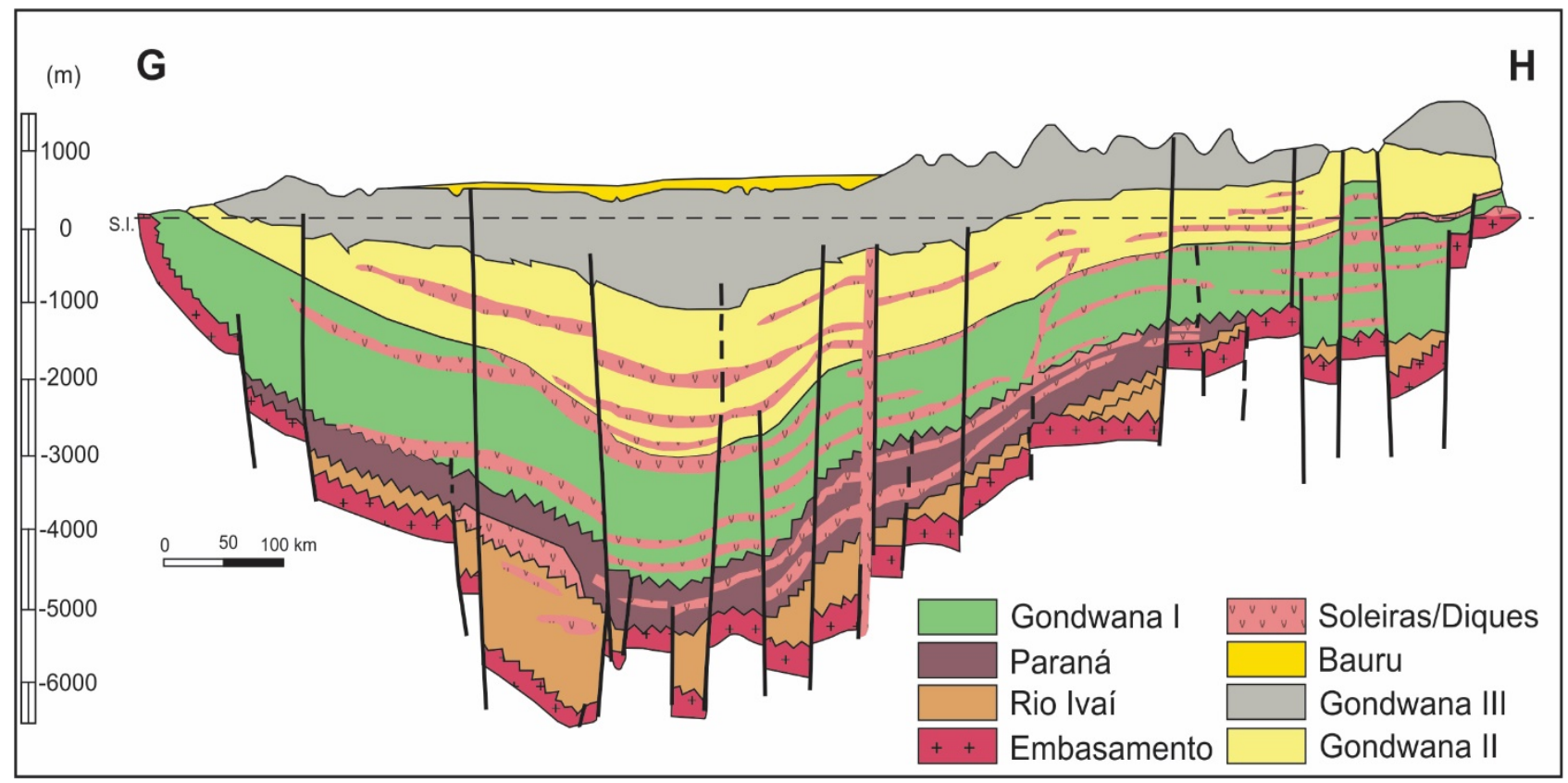

Figura 7 - Seção geológica esquemática da Bacia do Paraná (ver Figura 1) com as sequências deposicionais e as distribuições das soleiras nas rochas sedimentares (modificado de Milani \& Zalán, 1998).

A sequência Rio Ivaí (Meso-ordovicianoEossiluriano) é constituída pelas formações Alto Garças, Iapó e Vila Maria registrando a primeira incursão marinha da bacia. A Formação Vila Maria representa a máxima inundação do período (Milani et al., 1994, 2007 a,b) podendo ter até 362 m de espessura (Milani et al., 1990). A Formação Alto Garças de ambiente fluvial a marinho costeiro tem predomínio de arenitos com conglomerados na sua porção inferior e siltitos e argilitos na porção superior (Assine et al., 1994). Sobrepostos, os diamictitos da Formação Iapó indicam o estabelecimento de um ambiente glacial.

A sequência Paraná (Devoniano) é constituída pelas formações Furnas e Ponta Grossa e marca um segundo ciclo de incursões marinhas na bacia. A Formação Furnas registra uma assinatura transgressiva sendo constituída por arenitos de ambiente flúvio-deltaicomarinho (Assine et al., 1994). A Formação Ponta Grossa é o registro de uma segunda transgressão e dividida em três membros. O Membro Jaguariaíva é o registro inicial do afogamento dos sistemas transicionais da porção superior da Formação Furnas, sendo constituído por um folhelho preto, laminado, carbonoso e potencial gerador de hidrocarbonetos gasosos em toda a sua área de ocorrência na bacia (Milani et al., 2007a). O Membro Tibagi, síltico-arenoso reflete um contexto regressivo de progradação dos sistemas deltaicos. Os pelitos do Membro São Domingos indicam uma nova inundação em ampla escala (Milani et al., 2007a,b).

$\mathrm{Na}$ sequência Gondwana I (CarboníferoEotriássico) são descritas as formações Aquidauana, Lagoa Azul, Campo Mourão, Taciba, Rio Bonito, Palermo, Irati, Serra Alta, Teresina, Rio do Rastro, Piramboia e Sanga do Cabral (Figura 1) correspondentes a um ciclo transgressivo-regressivo completo e indicando a porção dominantemente paleozoica da Bacia (Milani et al., 1994, 2007a,b). A Formação Aquidauana com diamictitos intercalados com arenitos mostra um clima tendendo a glacial que se mantem durante a deposição das formações Lagoa Azul, Campo Mourão e Taciba.

A Formação Lagoa Azul são arenitos, diamictitos e folhelhos e na Formação Campo Mourão predominam arenitos e folhelhos enquanto a Formação Taciba tem folhelhos com intercalações de areia e diamictitos (França \& Potter, 1988a). Com o início do degelo há uma quebra do caráter transgressivo efetivamente 
implantado e imposição de um sistema regressivo com depósito das cunhas arenosas, siltitos, folhelhos e os carvões típicos da Formação Rio Bonito. A Formação Palermo registra então o início das incursões marinhas marcadas por siltitos e siltitos arenosos (Milani et al., 1994, 2007a, b). A Formação Irati mostra a sedimentação de folhelhos, folhelhos carbonosos, siltito, margas, carbonatos e anidrita em mar restrito com variações de salinidade (Mello et al., 1993). A Formação Irati é gradativamente "afogada" pela Formação Serra Alta com folhelhos representando novo ciclo regressivo e posterior continentalização marcada pelos argilitos, siltitos e calcários da Formação Teresina eventualmente depositados sob ação de ondas. A Formação Rio do Rastro é constituída por arenitos, siltitos e folhelhos indicativos do avanço de sistemas deltaicos sob uma crescente aridez. As formações Piramboia e Sanga do Cabral são arenitos variando de finos a médios raramente conglomeráticos de sistemas fluvio-eólicos associados a lagos rasos e localizados (Milani et al., 1994, 2007a,b).

A sequência Gondwana II (MesotriássicoNeotriássico) é representada pela Formação Santa Maria, com pelitos de origem lacustre e arenitos associados a um ambiente fluvial registrada somente na porção sul da bacia (Milani, 1997; Milani et al., 2007a).

A sequência Gondwana III (NeojurássicoEocretáceo) é composta pelas formações Botucatu e Serra Geral. A Formação Botucatu são os arenitos depositados em ambiente desértico e recobertos por até $2.000 \mathrm{~m}$ de derrames de composição básica a ácida da Formação Serra Geral, possuindo idade em torno de 130 Ma (Renne et al., 1992; Turner et al., 1994). Nesta formação, além dos derrames são descritas intrusões em forma de soleiras e diques, disseminadas por toda a bacia e associadas aos diferentes intervalos estratigráficos. As soleiras e diques com espessuras variando de alguns centímetros a centenas de metros, quando inseridas nas rochas geradoras da bacia, constituem fonte de calor suficiente para maturar o querogênio.

A sequência Bauru (Neocretáceo) é a unidade superior cujos depósitos siliciclásticos e paleoalterações correspondem a depósitos em ambiente árido a desértico.

Os folhelhos das formações Vila Maria, Ponta Grossa e Irati são as potenciais rochas geradoras da Bacia do Paraná. Especialmente nas formações Ponta Grossa e Irati, a maturação decorrente do efeito térmico causado pela dispersão de calor das intrusões ígneas parece contribuir significativamente para geração de óleo, condensado e gás (Milani et al., 1990, Araújo et al., 2000, Milani et al., 2007b).

Na Bacia do Paraná os sistemas petrolíferos atípicos que se destacam são Vila Maria-Alto Garças/Iapó (?), Vila Maria-Furnas (?), Ponta Grossa-Itararé (!), Irati-Piramboia (!) e Irati-Rio Bonito (!).

Análises de índice de alteração térmica (IAT) de amostras de folhelhos da Formação Irati obtidas em poços perfurados nos estados do Rio Grande do Sul e de Santa Catarina, mostram auréolas de contato equivalentes a três vezes à espessura da intrusão (Quadros, 1976). Contudo, outras evidências geoquímicas indicam que a influência térmica nas formações Ponta Grossa e Irati é diretamente proporcional a espessura do corpo ígneo intrusivo (Cerqueira \& Santos Neto, 1986; Santos Neto \& Cerqueira, 1990; Santos Neto, 1993; Araújo et al., 2000). Porém, estudos com base na análise do índice de coloração de esporos, dos biomarcadores, das análises por difração de raios $\mathrm{X}$, das análises petrográficas e de química mineral tem indicado que as intrusões ígneas afetam a rocha encaixante em aproximadamente metade da sua espessura (Souza et al., 2008; Anjos, 2008; Anjos \& Guimarães, 2008). Observa-se que nestas formações os resultados são conflitantes quanto à dimensão da auréola de contato e há necessidade de estudos mais detalhados.

A Bacia do Paraná não registra produção comercial de hidrocarbonetos, embora existam ocorrências de condensado e gás em reservatórios associados ao Grupo Itararé (que corresponde às formações Lagoa Azul, Campo Mourão e Taciba), constituindo o campo de Barra Bonita no interior do Paraná (Lucchesi, 1998). Os volumes in situ deste campo apresentam reservas estimadas em 2,7 milhões de metros cúbicos de condensado e 1,33 bilhão de metros cúbicos de gás (ANP, 2014), considerados subcomerciais.

Sistemas Petrolíferos da Bacia do Paraná

Os folhelhos das formações Vila Maria, Ponta Grossa e Irati são considerados como geradoras da Bacia do Paraná. A matéria orgânica da Formação Vila Maria embora não reconhecida como potencial geradora é 
composta por esporos, acritarcas, prasinófitos, quitinozoários e material amorfo. Já a Formação Vargas Peña que é a sequência correlata na porção paraguaia da bacia, os teores de carbono orgânico estão entre 1,7 e 2,0\% e IH variando entre 80 e $400 \mathrm{mg} \mathrm{HC/g}$ COT (Milani et al., 1990; Pereira et al., 2003) o que classifica o querogênio como do tipo II ou II/III. Os valores de Tmax são superiores a $440^{\circ} \mathrm{C}$ evidenciando assim que o querogênio encontra-se imaturo ou no limite imaturo/maturo (Pereira et al., 2003). Indícios de óleo e gás foram observados em poços na porção paraguaia da bacia (Milani et al., 1990) e fraturas em amostras de afloramento (Pereira et al., 2003) associados ao efeito térmico das intrusões ígneas na porção paraguaia da Bacia do Paraná.

A Formação Ponta Grossa (frasniana) tem aproximadamente $600 \mathrm{~m}$ de folhelhos e arenitos. Os teores de COT entre 1,5 e 3\% (Milani et al., 1998, Milani \& Zálan, 1999), com pico de 3\% e potencial gerador de até $6,0 \mathrm{~kg} \mathrm{HC} / \mathrm{t}$ rocha mostram este intervalo como o potencial gerador (Santos Neto \& Cerqueira, 1990). A matéria orgânica é constituída basicamente de matéria orgânica amorfa e lenhosa, com valores de índice de hidrogênio em torno de 300 mg HC/g COT e índice de oxigênio de até $100 \mathrm{mg} \mathrm{CO} / \mathrm{g} \mathrm{COT}$, classificando o querogênio como sendo do tipo II ou II/III (Santos Neto \& Cerqueira, 1995; Milani \& Zálan, 1999). São valores que sugerem que a matéria orgânica foi depositada em ambiente sob condições óxicas que são corroboradas pelas bioturbações, dos fósseis de invertebrados e do potencial principalmente para geração de gás (Santos Neto \& Cerqueira, 1990).

Considera-se que os folhelhos da Formação Ponta Grossa (ainda no Permiano) teriam sido soterrados até aproximadamente $2.000 \mathrm{~m}$ de profundidade, atingido temperatura mínima para geração de óleo. Posteriormente as intrusões ígneas contribuem para o aumento significativo da maturação, culminando com a geração de condensado e gás (Cerqueira \& Santos Neto, 1986; Santos Neto \& Cerqueira, 1990). Este fato leva Milani et al. (1998) a mostrar que os folhelhos desta formação estão no estágio senil em toda a bacia em decorrência do efeito térmico das intrusivas ígneas.

A Formação Irati tem espessura máxima de $150 \mathrm{~m}$ onde folhelhos e folhelhos betuminosos estão intercalados com carbonatos dolomíticos e siltitos (Araújo, 2001). Na porção basal desta formação, é reconhecido o Membro Taquaral e, na porção superior, o Membro Assistência (Barbosa \& Gomes, 1958). Os teores COT podem variar entre 0,5 e $13 \%$, com pico de $30 \%$. O potencial gerador é de $90 \mathrm{~kg} \mathrm{HC} / \mathrm{t}$ rocha (Espitalié et al., 1983; Milani \& Zálan, 1999; Araújo, 2001), chegando a $273 \mathrm{~kg} \mathrm{HC} / \mathrm{t}$ rocha (Santo Neto \& Cerqueira, 1990) indicando o Membro Assistência como o intervalo da Formação Irati com maior potencial gerador da bacia. A composição orgânica é basicamente matéria orgânica amorfa e palinomorfos, com valores de índice de hidrogênio muito elevados, entre 500 e $600 \mathrm{mg} \mathrm{HC} / \mathrm{g}$ COT, podendo chegar a $1.550 \mathrm{mg} \mathrm{HC} / \mathrm{g}$ COT pontualmente (Santos Neto, 1993), classificando o querogênio como sendo do tipo I (Silva \& Cornford, 1985; Milani \& Zálan, 1999). A preservação da matéria orgânica mostra que o ambiente deposicional tinha condições redutoras (Santos Neto, 1993; Araújo, 2001), o que permite que o Membro Assistência seja considerado como um excelente gerador de óleo.

Dois processos são os responsáveis pela geração de petróleo nas formações Ponta Grossa e Irati: (a) por soterramento no depocentro da bacia, sem influência direta de intrusivas ígneas e (b) por ação direta de intrusões ígneas (Milani et al., 1990; Zalán et al., 1990), contudo há autores que sugerem que a Formação Irati está imatura em toda a Bacia do Paraná (Araújo et al., 2000), segundo Milani et al., 2007b).

Os arenitos reservatórios da Bacia do Paraná com óleo e gás acumulados são da sequência deposicional Gondwana I no Grupo Itararé (formações Lagoa Azul, Campo Mourão e Taciba) e nas formações Rio Bonito e Piramboia. No entanto, admitindo-se que os folhelhos da Formação Vila Maria (Sequência Rio Ivaí) tenham potencial gerador e maturação térmica para geração (Milani et al., 1990; Pereira et al., 2003) seria admissível acumulações de hidrocarbonetos nos arenitos das formações Alto Garças, Iapó e também Furnas (Figura 1), caracterizando então os sistemas petrolíferos atípicos Vila Maria-Alto Garças/Iapó (?) e Vila Maria-Furnas (?) (Figura 8).

A Formação Alto Garças tem espessura máxima de 300 m (Milani et al., 2007a) e os arenitos da Formação Iapó, média de $20 \mathrm{~m}$ podendo chegar até $73 \mathrm{~m}$ (Assine et al., 1998), ambas com potencial para reservatório, embora não apresentam estudos relacionados a porosidade e permeabilidade. 


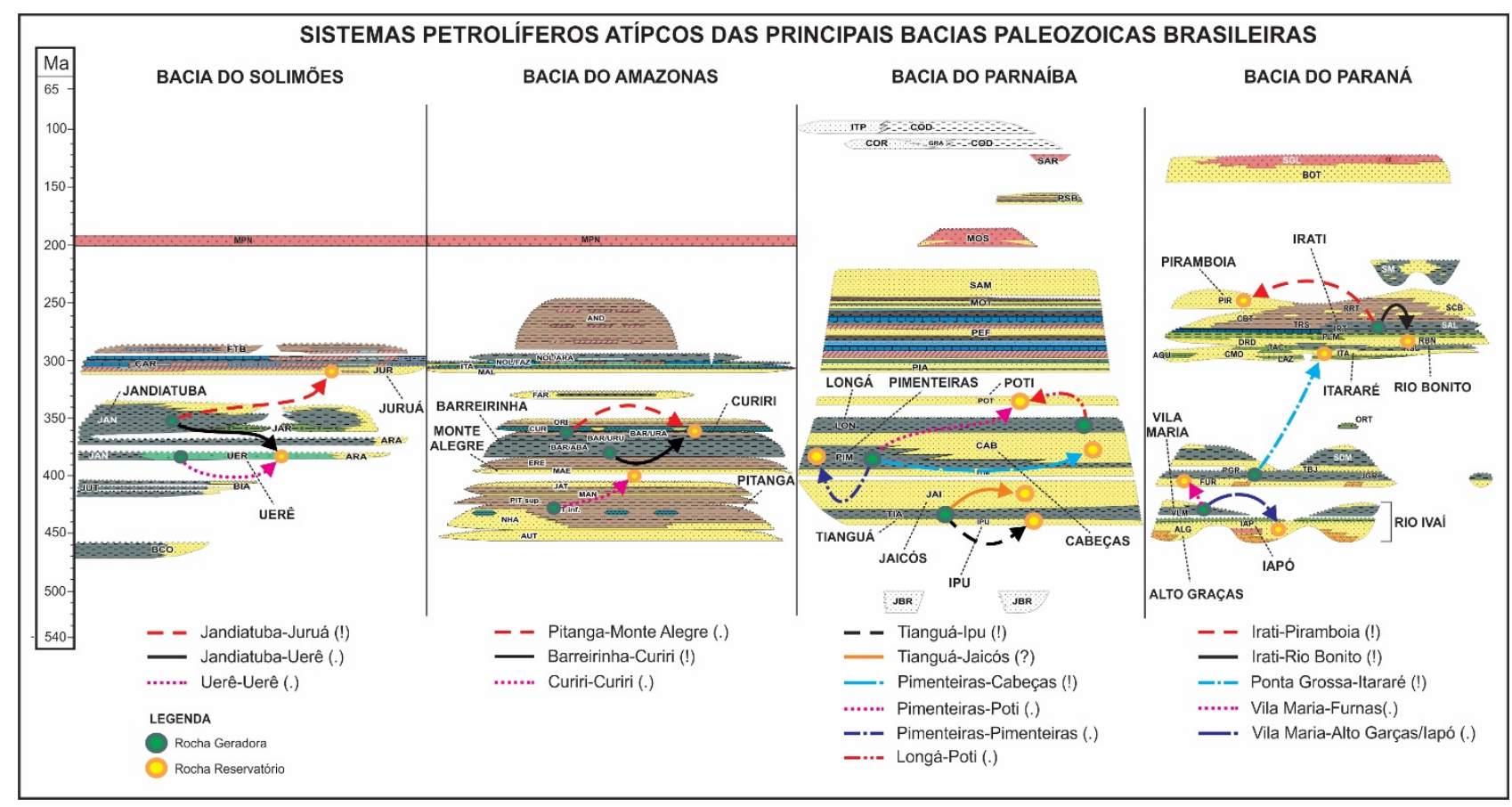

Figura 8 - Sistemas petrolíferos atípicos das principais bacias paleozoicas brasileiras (Solimões, Amazonas, Parnaíba e Paraná - modificado de Milani et al., 2007a).

Os arenitos da Formação Furnas com 230 a $260 \mathrm{~m}$ de espessura apresentam valores de porosidades entre 2 e 15,4\% (Lobato \& Borghi, 2004). Os pacotes de arenitos depositados em ambiente glacial do Grupo Itararé (formações Lagoa Azul, Campo Mourão e Taciba) e considerados reservatórios da bacia são constituídos pelas formações Aquidauana, Lagoa Azul, Campo Mourão e Taciba.

Os arenitos, siltitos e lamitos seixosos da Formação Lagoa Azul tem espessuras médias entre 200 e 400 m com máxima atingindo $560 \mathrm{~m}$ (França \& Potter, 1988a).

A Formação Campo Mourão trata-se de uma unidade predominantemente arenosa com espessas camadas variando entre 400 e $500 \mathrm{~m}$. Esta formação apresenta acumulações subcomerciais de condensado e gás gerados na Formação Ponta Grossa e armazenados em arenitos capeados por corpos de diabásio e camadas de folhelho (França \& Potter, 1988a; Luchessi, 1998). A Formação Taciba é composta por lamito seixoso, arenito, folhelho e algum siltito com espessura média variando entre 200 e $300 \mathrm{~m}$ chegando até a máxima observada que é de $420 \mathrm{~m}$ (França \& Potter, 1988a). Estes reservatórios arenosos tem porosidade média aproximada de $10 \%$ mas podem atingir até $30 \%$ e permeabilidade média de 0,55 mD (máxima de 2,85 mD).

Localmente, apresentam declínio dos valores de porosidade e permeabilidade relacionados à presença de argila, da seleção dos grãos e de cimento carbonático (França \& Potter, 1988b; Vidal, 2002; França, 2017). Resultados da determinação de razões isotópicas de carbono no metano dos gases deste reservatório mostram que a geração ocorreu na Formação Ponta Grossa, sendo os níveis de maturação térmica elevados observados, indícios de aquecimento relacionado à presença de intrusões ígneas (Santos Neto et al., 2001), caracterizando o sistema petrolífero Ponta Grossa-Itararé (!).

Os óleos encontrados nos reservatórios da Formação Rio Bonito provem da Formação Irati com elevada evolução térmica, com fortes indícios que foram gerados através do efeito térmico imposto pelas soleiras ígneas (ThomazFilho, 1982; Cerqueira \& Santos Neto, 1986; Santos Neto \& Cerqueira, 1990; Milani et al., 1998; Araújo et al., 2000; Araújo, 2001; Loutfi et al., 2010), sendo então o sistema petrolífero Irati-Rio Bonito (!).

Os óleos acumulados nos reservatórios da Formação Piramboia são imaturos, pesados (cerca de $5^{\circ} \mathrm{API}$ ), com alta viscosidade, elevado teor de enxofre e suas assinaturas isotópicas e geoquímicas (razões de biomarcadores) são associados a influência térmica na Formação Irati (Thomaz-Filho, 1982; Cerqueira \& Santos Neto, 1986; Santos Neto \& Cerqueira, 1990; Araújo et al., 2000; Araújo, 2001). Estes óleos pesados têm sua origem relacionada à degradação por 
bactérias e/ou oxigênio (biodegradação e/ou oxidação) em reservatório (Milani \& Catto, 1998; Cabral, 2006; Garcia et al., 2011; Costa et al., 2013), caracterizando a existência do sistema petrolífero Irati-Piramboia (!).
A figura 8 e a tabela 2 sumarizam os sistemas petrolíferos atípicos das principais bacias paleozoicas brasileiras, mostrando que o magmatismo intrusivo tem papel fundamental nestas bacias para geração e acumulação de petróleo.

Tabela 2 - Resumo dos sistemas petrolíferos atípicos das principais bacias paleozoicas brasileiras.

\begin{tabular}{|c|c|c|c|c|c|}
\hline BACIA & SISTEMA PETROLÍFERO & GERADORA & RESERVATÓRIO & $\begin{array}{l}\text { AURÉOLA DE } \\
\text { CONTATO }\end{array}$ & $\begin{array}{c}\text { IDADE DAS } \\
\text { SOLEIRAS (Ma) }\end{array}$ \\
\hline \multirow{3}{*}{ SOLIMÕES } & Jandiatuba-Juruá (!) & Jandiatuba & Juruá & Conhecida & \multirow{3}{*}{200} \\
\hline & Jandiatuba- Uerê (.) & Jandiatuba & Uerê & Conhecida & \\
\hline & Uerê-Uerê (.) & Uerê & Uerê & Desconhecida & \\
\hline \multirow{3}{*}{ AMAZONAS } & Pitanga-Monte Alegre (.) & Pitanga & Monte Alegre & Desconhecida & \multirow{3}{*}{200} \\
\hline & Barreirinha-Curiri (!) & Barreirinha & Curiri & Desconhecida & \\
\hline & Curiri-Curiri (.) & Curiri & Curiri & Desconhecida & \\
\hline \multirow{6}{*}{ PARNAÍBA } & Tianguá-Ipu (!) & Tianguá & Ipu & Desconhecida & \multirow{6}{*}{200 e 130} \\
\hline & Tianguá-Jaicós (?) & Tianguá & Jaicós & Desconhecida & \\
\hline & Pimenteiras-Cabeças (!) & Pimenteiras & Cabeças & Conhecida & \\
\hline & Pimenteiras-Poti (.) & Pimenteiras & Poti & Conhecida & \\
\hline & Pimenteiras-Pimenteiras (.) & Pimenteiras & Pimenteiras & Conhecida & \\
\hline & Longá-Poti (.) & Longá & Poti & Desconhecida & \\
\hline \multirow{5}{*}{ PARANÁ } & Vila Maria-Alto Garças/Iapó (.) & Vila Maria & Alto Garças/Iapó & Desconhecida & \multirow{5}{*}{130} \\
\hline & Vila Maria/Furnas (.) & Vila Maria & Furnas & Desconhecida & \\
\hline & Ponta Grossa-Itararé (!) & $\begin{array}{l}\text { Ponta } \\
\text { Grossa }\end{array}$ & Itararé & Conhecida & \\
\hline & Irati-Piramboia (!) & Irati & Piramboia & Conhecida & \\
\hline & Irati-Rio Bonito(!) & Irati & Rio Bonito & Conhecida & \\
\hline
\end{tabular}

\section{CONSIDERAÇÕES FINAIS}

Intrusões ígneas associadas a eventos magmáticos nas bacias sedimentares paleozoicas são essenciais para geração de petróleo atípica, principalmente em locais da bacia onde as rochas geradoras não alcançaram soterramento suficiente ou encontram-se em estágios iniciais de evolução térmica por soterramento.

A avaliação da evolução térmica de rochas geradoras afetadas termicamente pelo calor emanado por soleiras em bacias paleozoicas brasileira é prejudicada pela escassez de dados básicos de maturação, como por exemplo, refletância de vitrinita, índice de coloração de esporos e biomarcadores

Estudos detalhados de geoquímica orgânica e inorgânica que identifiquem o efeito térmico de intrusões ígneas em rochas geradoras de hidrocarbonetos ainda são poucos e devem ser realizados rotineiramente, auxiliando na identificação da auréola de contato com objetivo de contribuir na quantificação de rochas geradoras inseridas nas janelas de geração de óleo e gás.

A identificação dos sistemas petrolíferos nas bacias paleozoicas brasileiras ainda é discutível, mas observa-se que as novas técnicas de simulação numérica podem configurar uma nova e importante ferramenta de análise.A simulação numérica pode auxiliar na determinação da auréola de contato em locais onde os dados geológicos são inexistentes ou escassos tendo potencial para ser utilizada rotineiramente não só em pesquisas acadêmicas, mas também em empresas de exploração de hidrocarbonetos para mensurar o efeito térmico da dispersão de calor das soleiras nas rochas encaixantes.

Os principais sistemas petrolíferos atípicos existentes ou com possibilidade de ocorrência nas bacias paleozoicas brasileiras são:

(1) Bacia do Paraná: Vila Maria-Alto Garças/Iapó (?), Vila Maria-Furnas (?), Ponta Grossa-Itararé (!), Irati-Piramboia (!) e Irati-Rio Bonito (!);

(2) Bacia do Parnaíba: Tianguá-Ipu (?), Tianguá-Jaicós (?), Pimenteiras-Cabeças (!), Pimenteiras-Poti (!), Pimenteiras-Pimenteiras (?) e Longá-Poti (?);

(3) Bacia do Amazonas: Pitanga-Monte Alegre (.), Barreirinha-Curiri (!) e Curiri-Curiri (.); (4) Bacia do Solimões: Jandiatuba-Juruá (!), Jandiatuba-Uerê (.) e Uerê-Uerê 


\section{AGRADECIMENTOS}

Os autores agradecem ao CNPq pelo auxílio (processo GP 483331/13) que permitiu a realização deste artigo, parte da tese de doutorado do primeiro autor.

\section{REFERÊNCIAS}

AARNES, I. Sill emplacement and contact metamorphism in sedimentary basins - Local processes with global implications. Oslo, 2010. 181 p. Tese (Doutorado em Matemática e Ciências Naturais) - Faculty of Mathematics and Natural Sciences, University of Oslo.

AARNES, I.; SVENSEN, H.; POLTEAU, S.; PLANKE, S. Contact metamorphic devolatilization of shales in the Karoo Basin, South Africa, and the effects of multiple sill intrusions. Chemical Geology, v. 281, p. 181-194, 2011.

AGHAEI, H.; GURBA, L.W.; WARD, C.R.; HALL, M.; MAHMUD, S.A. Effects of igneous intrusions on thermal maturity of carbonaceous fluvial sediments: A case study of the Early Cretaceous Strzelecki Group in west Gippsland, Victoria, Australia. International Journal of Coal Geology, v. 152, p. 68-77, 2015.

AGIRREZABALA. L.M.; PERMANYER, A.; SUÁREZ-RUIZ, I.; DORRONSORO, C. Contact metamorphism of organicrich mudstones and carbon release around a magmatic sill in the Basque-Cantabrian Basin, western Pyrenees. Organic Geochemistry, v. 69, p. 26-35, 2014.

ALALADE, B. \& TYSON, R.V. Influence of igneous intrusions on thermal maturity of Late Cretaceous shales in the Tuma well, Chad Basin, NE Nigeria. Journal of African Earth Sciences, v. 77, p. 59-66, 2013.

ALVES, D.B. \& RODRIGUES, R. Influência das Intrusões Ígneas nos Folhelhos Devonianos da Bacia do Baixo Amazonas. Revista Brasileira de Geociências. v. 15, n. 2, p. 110-115, 1985.

AMARAL, P.F.; HIDALGO, R.; BARBOSA, R.C.M; NOGUEIRA, A.C.R. Palinomorfos da Formação Pimenteiras (Devoniano): Contribuição na Avaliação do Potencial de Geração de petróleo da Borda Oeste da Bacia do Parnaíba, Região de Pedro Afonso (TO). In: SIMPÓSIO DE GEOLOGIA DA AMAZÔNIA, 13, 2013, Belém. Resumos Expandidos... Belém: Sociedade Brasileira de Geologia Núcleo Norte, 2013, 3p.

ANJOS, C.W.D. \& GUIMARÃES, E.M. Metamorfismo de contato nas rochas da Formação Irati (Permiano), norte da Bacia do Paraná. Revista Brasileira de Geociências, v. 38, n. 4, p. 629-641, 2008.

ANJOS, C.W.D. Fatores Condicionantes nas Gêneses dos Argilominerais dos Folhelhos Negros e Pelitos Associados da Formação Irati no Norte da Bacia do Paraná. Brasília, 2008. 124 p. Tese (Doutorado em Geociências) - Instituto de Geociências. Universidade Federal de Brasília.

ANP. Área de Barra Bonita. Disp. em: www.anp.gov.br/SITE/acao/download/?id=71591 (acesso em 02/04/2018 - 09h24min). Agência Nacional do Petróleo, 2014

ANP. Plano de Desenvolvimento do Campo de Gavião Real. Disp.

http://www.anp.gov.br/wwwanp/images/planos desenvolvime nto/Gaviao_Real.pdf (acesso em 21/03/2018 - 14h38min). Agência Nacional do Petróleo, 2016a.

ANP. Plano de Desenvolvimento do Campo de Gavião Vermelho. Disp. em: http://www.anp.gov.br/wwwanp/images/planos_desenvolvime nto/Gaviao_Vermelho.pdf (acesso em 21/03/2018 14h40min). Agência Nacional do Petróleo, 2016b.

ANP. Plano de Desenvolvimento do Campo de Gavião Azul. Disp.

em: http://www.anp.gov.br/wwwanp/images/planos_desenvolvime nto/Gaviao_Azul.pdf (acesso em 21/03/2018 - 14h41min). Agência Nacional do Petróleo, 2016c.

ANP. Plano de Desenvolvimento do Campo de Gavião Branco.
http://www.anp.gov.br/wwwanp/images/EXPLORACAO_E_ PRODUCAO_DE_OLEO_E_GAS/Gestao_Contratos/Fase_Pr oducao/Planos_Desenvolvimento/Sumario-Executivo-

Externo-Gaviao-Branco.pdf (acesso em 21/03/2018 14h43min). Agência Nacional do Petróleo, 2016d.

ANP. Plano de Desenvolvimento do Campo de Gavião Preto. Disp. em: http://www.anp.gov.br/wwwanp/images/EXPLORACAO_E_ PRODUCAO_DE_OLEO_E_GAS/Gestao_Contratos/Fase_Pr oducao/Planos_Desenvolvimento/Sumario-Executivo-

Externo-Gaviao-Preto.pdf (acesso em 21/03/2018 14h345min). Agência Nacional do Petróleo, 2017.

ANP. Boletim de Recursos e Reservas de Petróleo e Gás Natural 2017. Agência Nacional do Petróleo/ANP. (Acesso em 11/09/2018 às 15h12min). Disp. em: (http://www.anp.gov.br/images/DADOS_ESTATISTICOS/Re servas/Boletim_Reservas_2017.pdf). Agência Nacional do Petróleo, 2018a.

ANP. Boletim Mensal de Produção de Petróleo e Gás Natural - Janeiro/2018. Agência Nacional do Petróleo/ANP. (Acesso em 25/03/2018 às 23h42min). Disp. em: (http://www.anp.gov.br/images/publicacoes/boletinsanp/Boletim_Mensal-

Producao_Petroleo_Gas_Natural/Boletim-Producao_janeiro2018.pdf). Agência Nacional do Petróleo, 2018b.

ARAÚJO, L.M. Análise da Expressão Estratigráfica dos Parâmetros de Geoquímica Orgânica e Inorgânica nas Sequências Irati. Porto Alegre, 2001. 301 p. Tese (Doutorado em Geociências) - Instituto de Geociências, Universidade Federal do Rio Grande do Sul.

ARAÚJO, L.M.; TRIGÜIS J.A.; CERQUEIRA J.R.; FREITAS C.S. The Atypical Permian Petroleum System of the Paraná Basin, Brazil. In: MELLO M.R. \& KATS B.J. (eds.). Petroleum system of South Atlantic margins. AAPG Memoir, v. 73, p. 377-402, 2000.

ASSINE, M.L.; ALVARENGA, C.J.S.; PERINOTTO, J.A.J. Formação Iapó: Glaciação Continental no Limite Ordoviciano/Siluriano da Bacia do Paraná. Revista Brasileira de Geociências, v. 28, n. 1, p. 51-60, 1998.

ASSINE, M.L.; SOARES, P.C.; MILANI, E.J. Sequências Tectono-Sedimentares Mesopaleozoicas da Bacia do Paraná, Sul do Brasil. Revista Brasileira de Geociências, v. 24, n. 2, p. 77-89, 1994.

BAKER, E. W.; HUANG, W. Y.; RANKIN, F. G.; CASTANO, J. R.; GUINN, J. R; FUEX, A. N. 1977. Electron Paramagnetic Ressonance Study of Thermal Alteration of Kerogen in Deep Sea Sediments by Basaltic Sill Intrusion. In: Initial Reports of the Deep Sea Drilling Project. Washington, National Science Foundation, v. XLI, p. 839-847. BARATA, C.F. \& CAPUTO, M.V. Geologia do Petróleo na Bacia Solimões - O Estado da Arte. In: CONGRESSO BRASILEIRO DE PESQUISA E DESENVOLVIMENTO EM PETRÓLEO E GÁS, 4, 2007. Campinas, Resumos Expandidos.... Campinas: Associação Brasileira de P\&D em Petróleo e Gás, 2007, p. 1-10.

BARbOSA, O. \& GOMES, F.A. Pesquisa de Petróleo na Bacia do Rio Corumbataí, Estado de São Paulo. Boletim da Divisão de Geologia e Mineralogia, Departamento Nacional de Produção Mineral, n. 171, 1958.

BARKER, C.E. \& BONE, Y. The Minimal Response to Contact Metamorphism by the Devonian Buchan Caves Limestone, Buchan Rift, Victoria, Australia. Organic Geochemistry, v. 22, n. 1, 151-164, 1995.

BARKER, C.E.; BONEY, Y.; LEWAN, M.D. Fluid inclusion and vitrinite-reflectance geothermometry compared to heat- 
flow models of maximum paleotemperature next to dikes, western onshore Gippsland Basin, Australia. International Journal of Coal Geology, v. 37, p. 73-111, 1998.

BATISTA, Z.V. Caracterização Faciológica, Petrográfica e Diagenética das Sequências Basais das Bacias do Parnaíba, Araripe, São José do Belmonte e Lavras da Mangabeira: Contribuição às Possíveis Correlações dos Arenitos Basais e suas Implicações Geotectônicas. Recife, 2015. 234 p. Tese (Doutorado em Geociências) - Universidade Federal de Pernambuco.

BENDER, A.A.; EIRAS, J.F.; WANDERLEY FILHO, J.R.; BARBOSA FILHO, C.M. Quantificação 3D da evolução termal da Bacia do Solimões e suas implicações petrolíferas. In: SIMPÓSIO DE GEOLOGIA DA AMAZÔNIA, 7, 2001, Belém. Resumos Expandidos...Belém: Sociedade Brasileira de Geologia, Núcleo Norte, 2001, p. 965-968, CD-ROM.

BISHOP, A.N. \& ABBOTT, G.D. The interrelationship of biological marker maturity parameters and molecular yields during contact metamorphism. Geochimica et Cosmochimica Acta, v. 57, p. 3661-3668, 1993.

BISHOP A.N. \& ABBOTT G.D. Vitrinite Reflectance and Molecular Geochemistry of Jurassic Sediments - the Influence of Heating by Tertiary Dykes (Northwest Scotland). Organic Geochemistry, v. 22, p. 165-177, 1995.

BOSTICK, N.H. Thermal Alteration of Clastic Particles as an Indicator of Contact and Burial Metamorphism in Sedimentary Rocks. Geoscience and Man, v. 3, p. 83-92, 1970.

BOSTICK N.H. \& PAWLEWICZ M.J. Paleotemperatures based on vitrinite reflectance of shales and limestones in igneous dike aureoles in the Upper Cretaceous Pierre Shale, Walsenburg, Colorado. In: WOODWARD, J.G.; MEISSNER, F.F.; CLAYTON, C.J. (eds). Hydrocarbon Source Rocks of the Greater Rocky Mountain Region. Rocky Mountain Association of Geologists, p. 387-392, 1984.

BROWN, R., GALLAGHER, K.; DUANE, M. A quantitative assessment of the effects of magmatism on the thermal history of the Karoo sedimentary sequence. Journal of African Earth Sciences, v. 18, p. 227-243, 1994.

CABRAL, C.V. Análise de Biomarcadores nos Arenitos Asfálticos da Borda Leste da Bacia do Paraná. Rio de Janeiro, 2006. 198 p. Dissertação (Mestrado em Engenharia Civil) -Universidade Federal do Rio de Janeiro.

CALDERÓN, S.M. Geoquímica Orgânica da Formação Barreirinha, Devoniano Superior da Bacia do Amazonas, Município de Rurópolis, PA: Implicações Paleoambientais e Avaliação do Potencial Gerador de Hidrocarbonetos. Belém, 2017. 90 p. Dissertação (Mestrado em Geologia) Universidade Federal do Pará.

CAPUTO, M.V. \& LIMA, E.C. Estratigrafia, Idade e Correlação do Grupo Serra Grande - Bacia do Parnaíba. In: CONGRESSO BRASILEIRO DE GEOLOGIA, 23, 1984. Rio de Janeiro, Resumos Expandidos... Rio de Janeiro: Sociedade Brasileira de Geologia, p. 740-753, 1984.

CAPUTO, M.V. \& SILVA, O.B. Sedimentação e Tectônica da Bacia do Solimões. In: RAJA GABAGLIA, G.P. \& MILANI, J.E. (Eds). Origem e Evolução de Bacias Sedimentares, p. 169-193, 1990.

CARDONA, Y.V. Avaliação dos Teores de Carbono Orgânico Total e Aspectos Composicionais dos Folhelhos Devoniano da Formação Longá, Bacia do Parnaíba, Brasil. São Paulo, 2015. 66 p. Dissertação (Mestrado em Geologia) Instituto de Geociências. Universidade de São Paulo.

CASTRO, L.O.C. \& SILVA, O.B. Ocorrência de Gás Sulfídrico na Bacia do Solimões - Modelo Geológico e Implicações. Boletim Geociências da Petrobras, v. 4, p. 285-298, 1990.

CERQUEIRA, J.R. \& SANTOS NETO, E.V. Papel das Intrusões de Diabásio no Processo de Geração de Hidrocarbonetos na Bacia do Paraná. In: CONGRESSO BRASILEIRO DE PETRÓLEO, 3, 1986. Rio de Janeiro. Resumos Expandidos, 16 p., 1986.

CLAYTON, J.L. \& BOSTICK, N.H. Temperature effects on kerogen and on molecular and isotopic composition of organic matter in Pierre Shale near an igneous dike. Organic Geochemistry, v. 10, p. 135-143, 1986.

COOPER, J.R.; CRELLING, J.C.; RIMMER, S.M.; WHITTINGTON, A.G. Coal metamorphism by igneous intrusion in the Raton Basin, CO and NM: Implications for generation of volatiles. International Journal of Coal Geology, v. 71, p. 15-27, 2007.

COSTA, F.L.; MARTINS, L.L.; CRUZ, G.F.; SANTOS, L.C.; SILVA, A.A. Caracterização Geoquímica Molecular de Arenitos Asfálticos a Partir da Desagregação Branda de Asfaltenos. Geochimica Brasiliensis, v. 27, n. 2, p. 161-172, 2013.

COSTA Jr, N.J.R. \& MAGALHÃES, E.S. 2016. Avaliação da Maturidade Térmica das Rochas Potencialmente Geradoras da Bacia do Parnaíba Utilizando Dados de Pirólise Rock-Eval e Carbono Orgânico Total. In: CONGRESSO BRASILEIRO DE GEOLOGIA, 48, 2016. Porto Alegre - RS. Resumo.... Porto Alegre: Sociedade Brasileira de Geologia. 1p, 2016.

CUNHA, P.R.C., GONZAGA, F.G., COUTINHO, L.F.C. FEIJÓ, F.J. Bacia do Amazonas. Boletim de Geociências da Petrobras, v. 8, n. 1, p. 47-55, 1994.

CUNHA, P.R.C., MELO, J.H.G., SILVA, O.B. Bacia do Amazonas. Boletim de Geociências da Petrobras, v. 15, n. 2, p. 227-251, 2007.

CUNHA, P.R.C.; BIANCHINI, A.R.; CALDEIRA, J.L.; MARTINS, C.C. Parnaíba Basin - The Awakening of a Giant. In: SIMPOSIO BOLIVARIANO - EXPLORACION PETROLERA EN LAS CUENCAS SUBANDINAS, $11^{\text {th }}$. Extended Abstract...., 2012.

DE ROS, L.F. \& GOLDBERG, K. Reservoir Petrofacies: A Tool for Quality Characterization and Prediction. In: AAPG ANNUAL CONVENTION, 2007, Long Beach, California. Abstract... Long Beach: 2007.

DECKART, K.; FERRAUD, G.; BETRAND, H. Age of Jurassic continental tholeiites of French Guyana, Surinam, and Guinea: Implications for the initial opening of the central Atlantic Ocean. Earth and Planetary Science Letters, v. 150, p. 205-220, 1999.

DECKART, K.; BERTRAND, H.; LIÉGEOIS, J.P. 2005. Geochemistry and $\mathrm{Sr}, \mathrm{Nd}, \mathrm{Pb}$ isotopic composition of the Central Atlantic Magmatic Province (CAMP) in Guyana and Guinea. Lithos, v. 82, p. 289-314, 2005.

DOW, W.G. Kerogen Studies and Geological Interpretations. Journal of Geochemical Exploration, v. 7, p. 79-99, 1977.

DRITS V.A.; LINDGREEN H.; SAKHAROV B.A.; JAKOBSEN H.J.; FALLICK A.E.; SALYN A.L.; DAINYAK L.G.; ZVIAGINA B.B.; BARFOD D.N. Formation and transformation of mixed-layer minerals by tertiary intrusives in cretaceous mudstones, West Greenland. Clays and Clay Minerals, v. 55, p. 260-283, 2007.

DUTROW, B.L.; TRAVIS, B.J.; GABLE, C.W.; HENRY, D.J. Coupled heat and silica transport associated with dike intrusion into sedimentary rock: Effects on isotherm location and permeability evolution. Geochimica et Cosmochimica Acta, v. 65, n. 21, p. 3749-3767, 2001.

EIRAS, J.F. Tectonics, Sedimentation and Petroleum System of the Solimões Basin, Amazon State. Geological Setting of Sedimentary Basins in Brazil - Searching for oil and gas in the land of giants. Schlumberger, p. 23-31, 1998.

EIRAS, J. F. Geologia e sistemas petrolíferos da Bacia do Solimões. In: SIMPÓSIO DE GEOLOGIA DA AMAZÔNIA, 6, 1999, Manaus. Resumos expandidos...Manaus. Sociedade Brasileira de Geologia, Núcleo Norte, 1999, p. 30-32.

EIRAS, J.F.; BECKER, C.R.; SOUZA, E.M.; GONZAGA, F.G.; SILVA J.G.F.; DANIEL, L.M.F.; MATSUDA, N.S.; FEIJÓ, F.J. Bacia do Solimões. Boletim de Geociências da Petrobras, v. 8, n. 1, p. 17-45, 1994.

EIRAS, J.F., \& WANDERLEY FILHO, J.R. Sistemas Petrolíferos Ígneo-Sedimentares. In: CONGRESSO BRASILEIRO DE PESQUISA E DESENVOLVIMENTO 
EM PETRÓLEO E GÁS, 2, 2003, Resumos Expandidos... Rio de Janeiro, 2003.

ESPITALIE, J.; MIZUTA, K.; CARVALHO, T.E.M.; TRIGÜIS, J.A. Oil Migration Examples in Irati Formation, Paraná Basin, Brazil. AAPG Bulletin, v. 67, n. 3, 457, 1983.

ETUK, E.E.; UKPABI, N.; UKAEGBU, V.U.; AKPABIO, I.O. Structural Evolution, Magmatism, and Effects of Hydrocarbon Maturation in Lower Benue Trough, Nigeria: A Case Study of Lokpaukwu, Uturu, and Ishiagu. The Pacific Journal of Science and Technology, v. 9, n. 2, 526-532, 2008.

FERREIRA, A.; RIGUETI, A.; BASTOS, G. BACIA DO AMAZONAS: Sumário Geológico e Setores em Oferta. $13^{\mathrm{a}}$ Rodada de Licitações de Petróleo e Gás. 17 p. Acesso em: $11 / 09 / 2018$ Disp. em: http://rodadas.anp.gov.br/arquivos/Round_13/areas_oferecidas _r13/Sumarios_Geologicos/Sumario_Geologico_Bacia_Amaz onas_R13.pdf, 2015.

FIGUEIREDO, A.M. \& MILANI, E.J. Petroleum systems of South America basins. In: CORDANI, U.G.; MILANI, E.J.; TOMAZ FILHO, A.; CAMPOS, D.A. (Eds.). Tectonic Evolution of South America, p. 689-718, 2000.

FINKELMAN, R.B., BOSTICK, N.H., DULONG, F.T., SENFTLE, F.E., and THORPE, A.N. Influence of an igneous intrusion on the inorganic geochemistry of a bituminous coal from Pitkin County, Colorado. International Journal of Coal Geology, v. 36, p. 223-241, 1998.

FJELDSKAAR, W.; HELSET, H. M.; JOHANSEN, H.; GRUNNALEITE, I.; HORSTAD, I. Thermal Modelling of Magmatic Intrusions in the Gjallar Ridge, Norwegian Sea: Implications for Vitrinite Reflectance and Hydrocarbon Maturation. Basin Research, v. 20, p. 143-159, 2008.

FRANÇA, R. Caracterização Petrofísica e Petrográgica de Arenitos do Poço 1-PN-14- SC-02: Formação Rio Bonito Bacia do Paraná. Niterói, 2017. 90 p. Monografia (Conclusão de Curso em Geofísica) -Universidade Federal Fluminense.

FRANÇA, A.B. \& POTTER, P.E. Estratigrafia, ambiente deposicional do Grupo Itararé (Permocarbonífero), Bacia do Paraná (Parte 1). Boletim Geociências Petrobras, v. 29, n. 2/4, 147-191, 1988a.

FRANÇA, A.B. \& POTTER, P.E. Estratigrafia, ambiente deposicional do Grupo Itararé (Permocarbonífero), Bacia do Paraná (Parte 2). Boletim Geociências Petrobras, v. 3, 1728, 1988b.

GALUSHKIN, Y. I., Thermal effects of igneous intrusions on maturity of organic matter: A possible mechanism of intrusion. Organic Geochemistry, v. 26, n. 11/12, p. 645-658, 1997.

GARCIA, P.H.V. Geoquímica Orgânica das Formações Ererê, Barreirinha e Curiri (Mese e Neodevoniano) em Dois Poços na Porção Oeste da Bacia do Amazonas. Rio de Janeiro, 2014. 130 p. Dissertação (Mestrado em Análise de Bacias e Faixas Móveis) -Universidade do Estado do Rio de Janeiro.

GARCIA, M.A.; RIBEIRO, H.J.P.S.; SOUZA, E.S.; TRIGÜIS, J.A. Correlação entre a Faciológia e a Geoquímica Orgânica dos Tar Sands da Formação Piramboia, Triássico da Bacia do Paraná, Fazenda Betumita, no Estado de São Paulo. Revista de Geociências UNESP, v. 30, n. 3, p. 357-369, 2011.

GARCIA, G.; ARAÚJO, L.M.; WANDERLEY FILHO, J.R 2012. Basin Modeling Uncertainties Related to the Hybrid Devonian Petroleum System (Conventional Plus Atypical) of the Solimões Basin (Brazil). In: AAPG HEDBERG CONFERENCE, PETROLEUM SYSTEMS: MODELING THE PAST, 1-5 October 2012, Nice, France. Extended Abstract... Nice, 2012, 5p.

GEORGE, S.G. Effect of igneous intrusion on the organic geochemistry of a siltstone and an oil shale horizon in the Midland Valley of Scotland. Organic Geochemistry, v. 18, n. 5, p. 705-723, 1992.

GILBERT, T.D.; STEPHENSON, L.C.; PHILP, R.P. Effect of a dolerite intrusion on triterpane stereochemistry and kerogen in
Rundle oil shale, Australia. Organic Geochemistry, v. 8, n. 2, p. 163-169, 1985.

GÓES. A.M.O. A Formação Poti (Carbonífero Inferior) da Bacia do Parnaíba. São Paulo, 1995. 171 p. Tese (Doutorado em Geociências) -Institute de Geociências, Universidade de São Paulo.

GÓES, A.M.O.; SOUZA, J.M.P.; TEIXEIRA, L.B. Estágio Exploratório e Perspectivas Petrolíferas na Bacia do Parnaíba. Boletim de Geociências da Petrobras, v. 4, n. 1, p. 55-64, 1990.

GOLAB, A.N., CARR, P.F., and PALAMARA, D.R. Influence of localized igneous activity on cleat dawsonite formation in Late Permian coal measures, Upper Hunter Valley, Australia. International Journal of Coal Geology, v. 66, p. 296-304, 2006.

GONZAGA, F.G., GONÇALVES, F.T.T., COUTINHO, L.F.C. Petroleum geology of the Amazonas Basin, Brazil: modeling of hydrocarbon generation and migration. In: M.R. Mello \& B. J. Katz (eds.). Petroleum Systems of South Atlantic Margins. AAPG Memoir 73, p. 159-178, 2000.

GONZÁLEZ, A.C.C. Influencia Térmica de Intrusões de Diabásio nas Camadas de Carvão e Rochas Sedimentares Encaixantes da Jazida de Santa Terezinha, Rio Grande do Sul. Porto Alegre, 2015. 104 p. Dissertação (Mestrado em Geociências) - Instituto de Geociências. Universidade Federal do Rio Grande do Sul.

GRÖCKE, D.R.; RIMMER, S.M.; YOKSOULIAN, L.E.; CAIRNCROSS, B.; TSIKOS, H.; VAN HUNEN, J. No evidence for thermogenic methane release in coal from the Karoo-Ferrar large igneous province. Earth and Planetary Science Letters, v. 277, p. 204-212, 2009.

GURBA, L.W. \& WEBER, C.R. Effects of igneous intrusions on coalbed methane potential, Gunnedah Basin, Australia. International Journal of Coal Geology, v. 46, p. 113-131, 2001.

ISSLER, R.S., ANDRADE, A.R.F., MONTALVÃO, R.M.G., GUIMARÃES, G., SILVA, G.G., LIMA, M.I.C. Geologia da folha S.A.22. Belém, Brasil. Departamento Nacional de Produção Mineral, Projeto RADAM BRASIL, DNPM. Rio de Janeiro, v. 5, p. 1-60, 1974.

JAEGER, J.C. Temperatures outside a cooling intrusive sheet. American Journal of Science, v. 257, p. 44-54, 1959.

KINGSTON, J. \& MATZKO, J.R. Undiscovered Petroleum of the Brazilian Interior Sag Basins. International Geology Review, v. 37, p. 959-980, 1995.

LEVORSEN, A.I. Geology of Petroleum. San Francisco, W.H. Freeman, 703 p, 1957.

LEYTHAEUSER, D.; ALTEBÄUMER, F. J.; SCHAEFER, R. G. Effect of an igneous intrusion on maturation of organic matter in Lower Jurassic Shales from NW-Germany. Physics and Chemistry of the Earth, v. 12, p. 133-139, 1980

LIMA, E.A. \& LEITE, J.F. Projeto de Estudo Global dos Recursos Minerais da Bacia Sedimentar do Parnaíba: Integração Geológico-Metalogenética. Relatório Final da Etapa III. Recife: Companhia de Pesquisa e Recursos Minerais, 212 p., 1978.

LITVINOVSKI B.A.; PODLADCHIKOV Y.Y.; ZANVILEVITCH A.N.; DUNITCHEV V.M. On the melting of acidic volcanites in the contact of basic magma at shallow depth. Geochimya, v. 6, p. 807-814, 1990.

LOBATO, G. \& BORGHI, L. 2004. Análise Estratigráfica da Formação Furnas (Devoniano Inferior) em Afloramentos da Borda Leste da Bacia do Paraná). In: CONGRESSO BRASILEIRO DE P\&D EM PETRÓLEO E GÁS, 3, 2005. Resumos Expandidos...Salvador: Sociedade Brasileira de Geologia, 2005, 6 p.

LOUTFI, I.S.; PEREIRA. E.; RODRIGUES, R.; CARDOZO, C.L. Controle Tectonoestratigráfico dos Processos de Geração, Migração e Trapeamento do Sistema Petrolífero Irati-Rio Bonito, na Região Carbonífera de Santa Catarina. Boletim Geociências da Petrobras, v. 18, n. 2, p. 271-290, 2010. 
LUCCHESI, C.F. Petróleo. Estudos Avançados, v. 12, n. 33, 17-40, 1998.

MAGOON, L.B. \& DOW, W.G. The Petroleum System. In: MAGOON, L.B. \& DOW, W.G. (eds.). The Petroleum Systems - From Source to Trap. AAPG Memoir, v. 60, p. 324, 1994.

MAKHOUS, M. \& GALUSHKIN, Y.I. Basin Analysis and Modeling of Burial, Thermal, and Maturation Histories in Sedimentary Basins. Editions Tecnip, Paris, 380 p, 2005.

MARZOLLI, A.; RENNE, P.R.; PICIRILLO, E.M.; ERNESTO, M.; BELLIENI, G.; MIN, A. Extensive 200-Million-year-old continental flood basalts of the Central Atlantic Magmatic Province. Science, v. 284, p. 616-618, 1999.

MASTALERZ, M.; DROBNIAK, A.; SCHIMMELMANN, A. Changes in optical properties, chemistry, and micropore and mesopore characteristics of bituminous coal at the contact with dikes in the Illinois Basin. International Journal of Coal Geology, v. 77, p. 310-319, 2009.

MAZ FILHO, A.; MIZUSAKI, A.M.P.; ANTONIOLI, L. Magmatism and petroleum exploration in the Brazilian Paleozoic Basins. Marine and Petroleum Geology, v. 25, p. 143-151, 2008a.

MELLO, M. R.; SANTOS NETO, E.V.; CERQUEIRA, J.R.; RODRIGUES, R.; GONÇALVES, T.T. The petroleum systems in the Brazilian Paleozoic basins: a biological marker approach. In: MANNING, D.A.C. (ed.), Organic geochemistry: Advances and Applications in Energy and the Natural Environment. Manchester University Press, Manchester, U.K., p. 76-78, 1991.

MELLO, M.R., KOUTSOUKOS, E.A.M., SANTOS NETO, E.V., TELLES JR, A.C.S. Geochemical and Micropaleontological Characterization of Lacustrine and Marine Hypersaline Environments from Brazilian Sedimentary Basins. In: KATZ, B.J. \& PRATT, L.M. (eds). Source Rocks in a Sequence Stratigraphic Framework. p. 17-34, 1993.

MEYERS P.A. \& SIMONEIT B.R.T. Effects of extreme heating on the elemental and isotopic compositions of an Upper Cretaceous coal. Organic Geochemistry, v. 30, p. 299-305, 1999.

MILANI, E.J. 1997. Evolução tectono-estratigráfica da Bacia do Paraná e seu relacionamento com a geodinâmica fanerozóica do Gondwana Sul-Ocidental. Porto Alegre, 1997. 255 p. (2v). Tese (Doutorado em Ciências) - Instituto de Geociências. Universidade Federal do Rio Grande do Sul.

Milani, E. J. \& Thomaz-Filho. A. Sedimentary basins of South America. In: CORDANI, U. G.; MILANI, E. J.; THOMAZFILHO A.; CAMPOS, D. A. (Eds). Tectonic evolution of South America. In: INTERNATIONAL GEOLOGICAL CONGRESS, 31, Rio de Janeiro, 2000. Proceeding...Rio de Janeiro: Sociedade Brasileira de Geologia, 2000, p. 389-449.

MILANI, E.J. \& CATTO, A.J. Petroleum Geology of the Paraná Basin, Brazil. In: ABGP/AAPG INTERNATIONAL CONFERENCE AND EXHIBITION, 1998. Rio de Janeiro. Abstract... Rio de Janeiro, 1998.

MILANI, E.J. \& ZALÁN, P.V. Brazilian Geology Part 1: the Geology of Paleozoic Cratonic Basins and Mesozoic Interior Rifts of Brazil. AAPG International Conference and Exhibition, American Association of Petroleum Geologists/Associação Brasileira de Geólogos de Petróleo, Rio' 98, Short Course Notes, Rio de Janeiro, Brasil, 1998.

MILANI, E.J. \& ZÁLAN, P.V. An outline of the geology and petroleum systems of the Paleozoic interior basins of South America. Episodes, v. 22, n. 3, p. 199-205, 1999.

MILANI, E.J.; KINOCHITA, E.M.; ARAÚJO, L.M.; CUNHA, P.R.C. Bacia do Paraná: Possibilidades Petrolíferas da Calha Central. Boletim de Geociências da Petrobras, v. 4, n. 1, p. 21-34, 1990.

MILANI, E.J.; FRANÇA, A.B.; SCHNEIDER, R.L. Bacia do Paraná. Boletim de Geociências da Petrobras, v. 8, n. 1, p. 69-82, 1994.
MILANI, E.J.; FACCINI, U.F.; SCHERER, C.M.; ARAÚJO, L.M.; CUPERTINO, J.A. Sequences and Stratigraphic Hierarchy of the Paraná Basin (Ordovician to Cretaceous), Southern Brazil. Boletim do Instituto de Geociências USP, v. 29, p. 125-173, 1998.

MILANI, E.J. \& ARAÚJO, L.M. Recursos Minerais Energéticos: Petróleo. In: BIZZI, L. A.; SCHOBBENHAUS, C.; VIDOTTI, R. M.; GONÇALVES, J. H. (eds.). Geologia, Tectônica e Recursos Minerais do Brasil, p. 551-576, 2003. MILANI, E.J.; MELO, J.H.G.; SOUZA, P.A.; FERNANDES, L.A.; FRANÇA, A.B. Bacia do Paraná. Boletim de Geociências da Petrobras, v. 15, n. 2, p. 265-287, 2007 a.

MILANI, E.J.; FRANÇA, A.B.; MEDEIROS, R.A. Rochas Geradoras e Rochas Reservatório da Bacia do Paraná, Faixa Oriental de Afloramentos, Estado do Paraná. Boletim de Geociências da Petrobras, v. 15, n. 1, p. 135-162, 2007b.

MIRANDA, F.S. 2014. Pimenteiras Shale: Characterization of an Atypical Unconventional Petroleum System, Parnaíba Basin, Brazil. In: AAPG INTERNATIONAL CONFERENCE \& EXHIBITION, 2014, Istanbul, Turkey. Abstract...Istanbul, 2014. Incompleto

MIZUSAKI, A.M.P.; THOMAZ-FILHO, A.; MILANI, E.J.; CÉSERO, P. Mesozoic and Cenozoic igneous activity and its tectonic control in northeastern Brazil. Journal of South America Earth Sciences, v. 15, p. 183-198, 2002.

MULLIN, R.P. Maturation model for middle Amazon Basin, Brazil: In: CONGRESSO BRASILEIRO DE GEOLOGIA, 25. 1988. Belém, Pará. Resumos Expandidos... Belém: Sociedade Brasileira de Geologia, 1988, v. 6, p. 2457-2471.

NEVES, C.A.O. Prospectos Potenciais e Áreas Prioritárias para Exploração na Bacia do Amazonas. Boletim de Geociências da Petrobras, v.4, n. 1, 95-103, 1990.

OTHMAN, R.; AROURI, K.R.; WARD, C.R.; MCKIRDY, D.M. Oil generation by igneous intrusions in the northern Gunnedah Basin, Australia. Organic Geochemistry, v. 32, p. 1219-1232, 2001.

PEREIRA, E.; RODRIGUES, R.; BRAZUTTI, D. Caracterização Geoquímica da Superfície de Inundação Máxima Llandoveniana na Parte Paraguaia da Bacia do Paraná. Geochimica Brasiliensis, v. 17, n. 1, p. 1-12, 2003.

PEREIRA, E.; CARNEIRO, C.D.R.; BERGAMASCHI, S.; ALMEIDA, F.F.M. Evolução das Sinéclises Paleozoicas, Províncias Solimões, Amazonas, Parnaíba e Paraná. In: HASUI, Y.; CARNEIRO, S.D.R.; ALMEIDA, F.F.M.; BARTORELLI, A. (eds). Geologia do Brasil, p. 374-394, 2012.

PERREGAARD, J. \& SCHIENER, E.J. Thermal Alteration of Sedimentary Organic Matter by a Basalt Intrusive. Chemical Geology, v. 26, p. 331-343, 1979.

PETERS K.E.; WHELAN J.K.; HUNT J.M.; TARAFA M.E. Programmed pyrolysis of organic matter from thermally altered Cretaceous black shales. AAPG Bulletin, v. 67, p. 2137-2146, 1983

POLYANSKY, O.P. \& REVERDATTO, V.V. Contact Metamorphism and Metasomatism near the Talnakh Intrusion: Fluid Convection and Heat Transfer Modeling on the Basis of the Finite-Difference Method. Doklady Earth Sciences, v. 411a, n. 9, p. 1480-1484, 2006.

PORTO, A.L. Mapeamento Sísmico de Intrusões Ígneas na Porção Sudeste da Bacia do Parnaíba e suas Implicações para um Modelo de Sistema Petrolífero Não-Convencional. Rio de Janeiro, 2013, 89 p. Monografia (Conclusão de Curso de Geologia). Faculdade de Geologia. Universidade do Estado do Rio de Janeiro.

QUADROS, L.P. Efeito das Intrusões Ígneas de Diabásio em Rochas Sedimentares do Leste e Sul da Bacia do Paraná. Boletim Técnico da Petrobras, v. 19, n. 3, p. 139-155, 1976.

RAYMOND, A.C. \& MURCHISON, D.G. Development of organic maturation in the thermal aureoles of sills and its relation to sediment compaction. Fuel, v. 67, p. 1599-1608, 1988. 
RENNE, P.R.; ERNESTO, M.; PACCA, I.G.; COE, R.S.; GLEN, J.M.; PREVOT, M.; AND PERRIN, M. The age of Paraná flood volcanism, rifting of Gondwanaland, and the Jurassic-Cretaceous boundary. Science, v. 258, p. 975-979, 1992.

RODRIGUES, R. Geoquímica Orgânica na bacia do Parnaíba. Revista Brasileira de Geociências, v. 25, p. 145-146. 1995.

RODRIGUES, R. \& QUADROS, L.P. Avaliação do Potencial Gerador das Bacias Paleozoicas Brasileiras. In: CONGRESSO BRASILEIRO DE PETRÓLEO, 2, 1982. Rio de Janeiro. Resumos Expandidos... Rio de Janeiro: IBP, 1982.

RODRÍGUEZ-MONREAL, F.; VILLAR, H.J.; BAUDINO, R.; DELPINO, D.; ZENCICH, S. Modeling an Atypical Petroleum System: A Case Study of Hydrocarbon Generation, Migration and Accumulation Related to Igneous Intrusions in the Neuquén Basin, Argentina. Marine and Petroleum Geology, v. 26, p. 590-605, 2009.

ROSSETTI, D.F.; TRUCKENBRODT, W.; SANTOS JR, A.E. Clima do cretáceo no meio-norte brasileiro. In: ROSSETTI, D.F.; GÓES, A.M.; TRUCKENBRODT, W. (Eds.). 0 Cretáceo na Bacia de São Luís-Grajaú, p. 67-76, 2001.

SANTOS NETO, E,V. Caracterização Geoquímica e Paleoambiente Deposicional da Sequência CabonatoPelítica Superior do Membro Assistência, Formação Irati no Estado de São Paulo, Bacia do Paraná. Rio de Janeiro, 1993. 203 p. Dissertação (Mestrado em Geologia) - Instituto de Geociências. Universidade Federal do Rio de Janeiro.

SANTOS NETO, E.V. \& CERQUEIRA, J.R. Avaliação Geoquímica da Bacia do Paraná. In: CONGRESSO BRASILEIRO DE PETRÓLEO, 4, 1990. Rio de Janeiro. Resumos expandidos... Rio de Janeiro: Sociedade Brasileira de Geologia, p. 1-7, 1990.

SANTOS NETO, E.V. \& CERQUEIRA, J.R. Source Rock Generative Potential of Upper Devonian Shales (Ponta Grossa Formation), Parana Basin, Brazil. In: AAPG ANNUAL CONVENTION, Houston, Texas, Abstract... Houston: AAPG, 1995.

SANTOS, R.V.; DANTAS, E.L.; OLIVEIRA, C.G.; ALVARENGA, C.J.S.; ANJOS, C.W.D. DOS; GUIMARÃES, E.D.; OLIVEIRA, F.B. Geochemical and thermal effects of a basic sill on black shales and limestones of the Permian Irati Formation. Journal of South American Earth Sciences, v. 28, p. 14-24, 2009.

SANTOS NETO, E.V.; CERQUEIRA, J.R.; TAKAKI, T.; PRINZHOFER, A. Ponta Grossa-Itararé: An Unusual Gas System in the Paraná Basin, Brazil. In: AAPG ANNUAL CONVENTION, Denver, Colorado, Abstract... Denver: AAPG, 2001.

SAXBY, J.D. \& STEPHENSON, L.C. Effect of an Igneous Intrusion on Oil Shale at Rundle (Australia). Chemical Geology, v. 63, p. 1-16, 1987.

SCHUTTER, S. R. Hydrocarbon Ocurrence and Exploration in and Around Igneous Rocks. In: PETFORD, N. \& MCCAFFREY, J.W. (eds). Hydrocarbons in Crystalline Rocks. Geological Society Special Publications, v. 214, p. 7 33, 2003.

SILVA, A.F.S.; BARROS, A.L.C.; LIMA, S.G. Geoquímica Molecular de Rochas Geradoras da Formação Barreirinha, Município Rurópolis - Pará, Bacia do Amazonas. In: CONGRESSO BRASILEIRO DE GEOQUÍMICA, 16, Búzios. Resumos Expandidos...Búzios: Sociedade Brasileira de Geologia, 4 p, 2017.

SILVA, Z.C.C. \& CORNFORD, C. The kerogen type, depositional environment and maturity, of the lrati Shale, Upper Permian of Paraná Basin, Southern Brazil. Organic Geochemistry, v. 8, n. 6, p. 399-411, 1985.

SIMONEIT, B.R.T; BRENNER, R.S.; PETERS, K.E.; KAPLAN, I.R. Thermal Alteration of Cretaceous Black Shale by Basaltic Intrusion in the Eastern Atlantic. Nature, v. 273, p. 501-504, 1968.

SIMONEIT, B.RT.; BRENNER, S.; PETERS, K.E.; KAPLAN,
I.R. Thermal alteration of Cretaceous black shale by diabase intrusions in the Eastern Atlantic - II. Effects on bitumen and kerogen. Geochimica et Cosmochimica Acta, v. 45, p. 15811602, 1981.

SNYMAN, C.P., BARCLAY, J. The coalification of South African coal. International Journal of Coal Geology, v. 13, p. 375-390, 1989.

SOUSA, J. J. F.; VUGMAN, N. V.; COSTA NETO, C. 1997. Free radical transformations in the Irati oil shale due to diabase Intrusion. Organic Geochemistry, v. 26, n. 3/4, p. 183-189, 1997.

SOUZA, I.V.A.F.; MENDONÇA FILHO, J.G.; MENEZES, T.R. Avaliação do efeito térmico das intrusivas ígneas em um horizonte potencialmente gerador da Bacia do Paraná: Formação Irati. Revista Brasileira de Geociências, v. 38, n. 2-supl., p. 138-148. 2008.

STEWART, A.K.; MASSEY, M.; PADGETT, P.L.; RIMMER, S.M.; HOWER, J.C. Influence of a basic intrusion on the vitrinite reflectance and chemistry of the Springfield (no. 5) coal, Harrisburg, Illinois. International Journal of Coal Geology, v. 63, p. 58-67, 2005.

SUCHÝ, V.; ŠAFANDA, J.; SÝKOROVÁ, I.; STEJSKAL, M.; MACHOVIČ, V.; MELKA, K. Contact metamorphism of Silurian black shales by a basalt sill: geological evidence and thermal modeling in the Barrandian Basin. Czech Geological Survey. Bulletin of Geosciences, v. 79, n. 3, p. 133-145, 2004.

SVENSEN, H.; PLANKE, S.; CHEVALLIER, L.; MALTHESØRENSSEN, A.; CORFU, F.; JAMTVEIT, B. Hydrothermal venting of greenhouse gases triggering Early Jurassic global warming. Earth and Planetary Science Letters, v. 256, p. 554566, 2007.

SWEENEY, J.J. \& BURNHAM, A.K. Evaluation of a simple model of vitrinite reflectance based on chemical kinetics. AAPG Bulletin, v. 74, n. 10, p. 1559-1570, 1990.

TASSINARI, C.C.G.; BETTENCOURT, J.S.; GERALDES M.C.; MACAMBIRA, M.J.B.; LAFON, J.M. The Amazon Craton. In: CORDANI, U.G.; MILANI, E.J.; THOMAZ FILHO, A.; CAMPOS, D.A. (eds). Tectonic Evolution of South America, p. 41-95, 2000.

TENÓRIO, M.F. Avaliação do Potencial Gerador e Caracterização de Biomarcadores em Afloramentos Rochosos do Vale do Rio Tapajós, Borda Sul da Bacia do Amazonas. Rio de Janeiro, 2013. 188 p. Dissertação (Mestrado em Engenharia). Programa de Pós-Graduação em Engenharia Civil, COPPE, da Universidade Federal do Rio de Janeiro.

THOTHOMAZ FILHO, A. Ocorrência de Arenito Betuminoso em Anhembi (SP): Cubagem e Condicionamento Geológico. In: CONGRESSO BRASILEIRO DE GEOLOGIA, 32 , Salvador. Salvador: Sociedade Brasileira de Geologia, 1982. Resumos Expandidos... Salvador: Sociedade Brasileira de Geologia, v. 5, p. 2344-2348, 1982.

THOMAZ FILHO, A.; MUZUSAKI, A.M.P.; MILANI, E.J.; CESARO, P. Rifting and Magmatism Associated with the South America and Africa Break Up. Revista Brasileira de Geociências, v. 30, n. 1, p. 17-19, 2000.

THOMAZ FILHO, A.; MIZUSAKI, A.M.P.; ANTONIOLI, L. Magmatismo nas Bacias Sedimentares Brasileiras e sua Influência na Geologia do Petróleo. Revista Brasileira de Geociências, v. 38, n. 2, p. 128-137, 2008.

TRIGÜIS J. A., RODRIGUES R., SOUZA E. Estratigrafia Química da Seção Tipo da Formação Barreirinha (Devoniano Superior), Bacia do Amazonas-Brasil. In: Congresso Brasileiro de Pesquisa e Desenvolvimento em Petróleo e Gás, 3, Salvador. Resumos Expandidos. p. 1-4, 2005.

Turner, S.; Regelous, M.; Kelley, S.; Hawkesworth, C.; Mantovani, M. Magmatism and continental break-up in the South Atlantic: high precision 40Ar-39Ar geochronology. Earth Planei. Sei. Lett., v. 124, p. 333-348, 1994.

UJIIÉ, Y. Contact-metamorphic effect on parameters for 
kerogen maturation. Organic Geochemistry, v. 9, n. 6, p. 375-378, 1986.

VIDAL, A.C. Estudo Hidrogeológico do Aquífero Tubarão na Área de Afloramento da Porção Central do Estado de São Paulo. Rio Claro, 2002. 109 p. Tese (Doutorado em Geociências) - Instituto de Geociências e Ciências Exatas, Universidade Estadual Paulista.

WANDERLEY FILHO, J.R.; TRAVASSOS, W.A.S.; ALVES, D.B. O diabásio nas bacias paleozoicas amazônicas - herói ou vilão. Boletim de Geociências Petrobras, v. 14, n. 1, p. 117 184, 2006.

WANDERLEY FILHO. J.R.; EIRAS, J.F.; VAZ, P.T. Bacia do Solimões. Boletim de Geociências Petrobras, v. 15, n. 2, p. 217-225, 2007.

WANG, D. MagmaHeatNS1D: One-dimensional visualization numerical simulator for computing thermal evolution in a contact metamorphic aureole. Computers \& Geosciences, v. 54, p. 21-27, 2013

WANG, D. \& SONG, Y. Influence of different boiling points of pore water around an igneous sill on the thermal evolution of the contact aureole. International Journal of Coal Geology, v. 104, p. 1-8, 2012.

WANG, X.; LERCHE, I.; WALTERS, C. The effect of igneous intrusive bodies on sedimentary thermal maturity. Organic Geochemistry, v. 14, n. 6, p. 571-584, 1989.

WANG, D.; SONG, Y.; LIU, Y.; ZHAO, M.; QI, T.; LIU, W. The influence of igneous intrusions on the peak temperatures of host rocks: Finite-time emplacement, evaporation, dehydration, and decarbonation. Computers \& Geosciences, v. 38, p. 99-106, 2012.

XU, C.; CHENG, Y.; WANG, L.; ZHOU, H. Experiments on the effects of igneous sills on the physical properties of coal and gas occurrence. Journal of Natural Gas Science and Engineering, v. 19, p. 98-104, 2014.
YOUNG, C.G.K. \& BORGHI, L. Pimenteiras Formation (Devonian, Parnaíba Basin): A New Prospect for Hydrocarbon Reservoirs. In: CONGRESSO BRASILEIRO DE PESQUISA E DESENVOLVIMENTO EM PETRÓLEO E GÁS, 2, 2003, Rio de Janeiro. Resumos Expandidos...Rio de Janeiro: Sociedade Brasileira de Geologia, 2003.

ZALÁN, P.V.; WOLFF, S.; CONCEIÇÃO, J.C.J.; MARQUES, Q.; ASTOLFI, M.A.M.; VIEIRA, I.S.; APPI, V.T.; ZANOTTO, O.A. Bacia do Paraná. In: Raja Gabaglia, G.P. \& Milani, E.J. (Eds.). Origem e Evolução de Bacias Sedimentares, p. 135-168, 1990.

ZHANG, X.L., CHENG, Y.P., WANG, L., ZHAO, W. Research on the controlling effects of a layered sill with different thicknesses on the underlying coal seam gas occurrence. Journal of Natural Gas Science and Engineering, v. 22, p. 406-414, 2015.

ZHU, D.; JIN, Z.; HU, W.; SONG, Y.; GAO, X. Effect of igneous activity on hydrocarbon source rocks in Jiyang subbasin, eastern China. Journal of Petroleum Science and Engineering, v. 59, p. 309-320, 2007
Submetido em 7 de abril de 2018 Aceito em 26 de janeiro de 2019 